\title{
Beiträge zur Kenntnis der Verwitterungsprodukte der Silikate in Ton-, Vulkanischen und Laterit-Böden.
}

\author{
Von \\ J. M. van BemMELEN.
}

Inhalt: \& I. Einleitung S. 265. \& II. Das Verhältnis zwischen $\mathbf{A l}_{2} \mathrm{O}_{8}$ und $\mathrm{SiO}_{2}$ S. 268. A. Alluviale plastische Tone S. 268. B. Böden eruptiven Ursprungs S. 270 . C. Lateritböden S. 273. \$ III. Folgerungen aus \$ II S. 281. § IV. Die alkalinischen Basen im Verwitterungssilikat S. 283 . \& V. Das Wasser im Verwitterungssilikat S. 285. \$ VI. Der löslichste Teil des Verwitterungssilikats S. 286. \$ VII. Die Löslichkeit des Verwitterungssilikats in Salzsäure S. 287. \$ VIII. Das Eisenoxyd im Boden S. 290. § IX. Der Wassergehalt des Eisenoxyds S. 296. \$ IX. Die Plastizität S. 298. \& X. Konstitution des Verwitterungssilikats S. 299. \& XI. Der Verwitterungsprozefs S. 302. Tabellen der Analysen I-XXV S. 305-314.

\section{\& I. Einleitung.}

Von der Zusammensetzung des Verwitterungsproduktes der kristallinischen Gesteine, aus welchen die Ackererde besteht, kann man behaupten, dafs sie bis jetzt noch so gut wie unbekannt war, trotz zahlloser Bodenanlysen. Eine Hauptursache davon ist ohne Zweifel. dals bei der Behandlung der Erde mit Säuren (Salz- oder Schwefel-) die ans dem Silikat freiwerdende Kieselsäure nicht bestimmt ist. ${ }^{1}$ Eine zweite Ursache ist diese, dafs nicht nachgespürt ist, was durch Ausziehung mit einem Alkali, und was durch Behandlung mit zunehmend stärkeren Säuren in Lösung kam. So ist erst vor kurzem durch BadER und nach ihm durch SchLösing bemerkt, dals es Böden gibt, worin die Alaunerde frei vorkommt, oder wo die Kieselsäure im Verwitterungssilikat gegenüber der Alaunerde zurücktritt, wie im Laterit der Fall ist, eine Bodenart, die in den Tropen vielfach beobachtet und auch wohl analysiert ist, ohne

1 Die Bauschanalysen waren noch viel weniger tauglich, um die $\mathrm{Zu}-$ sammensetzung der Gemengteile kennen zu lernen. Sie hatten dann auch einen anderen Zweck.

Z. anorg. Chem. Bd. 42. 
dafs man diese Eigentümlichkeit bemerkt hatte. ${ }^{1}$ Ohne Zweifel kommen an vielen Orten, auch aufser den Tropen, Bodenarten vor, deren Verwitterungssilikat viel $\mathrm{Al}_{2} \mathrm{O}_{3}$-reicher ist als im plastischen Ton, was früher unbekannt geblieben ist, weil man die Bestimmung der zugehörigen $\mathrm{SiO}_{2}$ nachgelassen hat. ${ }^{2}$

Diese Bestimmung ist jedoch leicht zu machen. Wird die Erde mit Salzsäure ausgezogen, dann löst sich nur ein Teil der Kieselsäure, welche aus dem Verwitterungssilikat freigeworden ist, und zwar um so weniger, je nachdem die Salzsäure konzentrierter ist. Alle Bestimmungen der Kieselsäure in den SalzsäureExtrakten, die früher gemacht sind, haben also gar keinen Wert. Wenn man jedoch nach der Behandlung mit Salzsäure, ja selbst nach Behandlung mit konzentrierter Schwefelsäure die Erde, während einzelner Minuten (3 genügt schon) mit verdünnter Kali- oder Natronlauge schüttelt, unter sanfter Erwärmung $( \pm 50 \%)$, dann löst sich die abgeschiedene und durch die Säure nicht gelöste Kieselsäure. Der Hydrosol von $\mathrm{SiO}_{2}$ nämlich löst sich ganz leicht bei dieser Temperatụr in verdünnter Lauge (von 1.04 spez. Gew.), auch wenn er ganz trocken geworden, ja selbst geglüht ist. Wird die Erde hintereinander mit Salzsäure von verschiedener Konzentration und schliefslich mit konzentrierter Schwefelsäure ausgezogen, dann kann man die Zusammensetzung des gelösten Teiles des Verwitterungssilikats jedesmal bestimmen, wenn man nur die kurze Behandlung mit verdünnter Lauge nach jeder Ausziehung ausführt. $^{3}$ Zuletzt müssen dann die ungelösten Teile mikroskopisch

1 Bauer ist der erste gewesen der in Jahre $1898 \mathrm{im}$ Laterit der Seychellen Inseln die freie Alaunerde aufgefunden hat. Neues Jahrbuch für Mineral. Geol. II, S. 163. Schlösinc (1901) hat in Ackererden auf Madagaskar und auch in Französischen Erden durch Ausziehen mit siedender verdünnter Natronlange viel Alaunerde auf wenig Kieselsäure nachgewiesen. Ich habe seine Zahlen auf Molek. umgerechnet. Er fand in drei Böden:

$$
7.0-4.2-2.5 \mathrm{Mol} . \mathrm{Al}_{2} \mathrm{O}_{8} \text { auf } 1 \mathrm{Mol} . \mathrm{SiO}_{2}
$$

oder $\quad 0.14-0.24-0.4 \mathrm{Mol} . \mathrm{SiO}_{2}$ auf $1 \mathrm{Mol}, \mathrm{Al}_{2} \mathrm{O}_{8}$

(Compt. rend. 132, 723).

2 Das geht so weit, dafs, wie Bauer sagt, die freie Alaunerde in Böden wohl mit Kaolin verwechselt ist. In Woultmanss Handbuch der tropischen Agrikultur (1892) wird über das Vorkommen von freier oder $\mathrm{SiO}_{2}$-armer Alaunerde nichts erwähnt, obgleich viele Analysen von Laterit mitgeteilt werden, die zwar in dieser Hinsicht ganz ungenïgend sind.

${ }^{3}$ 3-5 g Erde, sehr fein gerieben, wurden mit 50-100 ecm Salzsäure verschiedener Stärke während einer bestimmten Zeit auggezogen.

Im folgenden bedeuten die Buchstaben $a, b$ u. s. w. den Auszug mit; 
untersucht werden. ${ }^{1}$ Ist das Verwitterungssilikat sehr basisch, und dadurch schon in verdünnter Lauge löslich, so mufs eine Ausziehung damit der Ausziehung mit Säuren vorhergehen. In diesem Fall mufs diese Ausziehung eine längere Zeit fortgesetzt werden. Sonst, in den gewöhnlichen plastischen Tonböden, löst die Lauge keine oder nur ganz unbedeutende Mengen des Silikats, wenn sie eine so kurze Zeit mit der Erde in Berührung ist.

Diese Methode habe ich zum ersten mal vor 16 Jahren befolgt, bei der Analyse von Tonböden, in den neuen Alluvien der Niederlande und in vulkanischen Böden in Sumatra und auf Java (Ust Indien). Bei den ersten ergab es sich, dals im Verwitterungssilikat auf $1 \mathrm{Mol}$. $\mathrm{Al}_{3} \mathrm{O}_{3}$ drei bis fünf $\mathrm{Mol}$. $\mathrm{SiO}_{2}$ enthalten waren, aber bei einem vulkanischen Boden von Deli (Sumatra) ergab es sich, dafs fast das ganze Verwitterungssilikat leicht löslich in verdünnter Lauge war und sehr basisch, so dals es noch nicht $1 \mathrm{Mol}^{\mathrm{SiO}} \mathrm{S}_{2}$ auf $1 \mathrm{Mol}$. $\mathrm{Al}_{2} \mathrm{O}_{9}$ enthielt.

a Salzsäure von 1.035 spez. Gew. bei $55^{\circ}$ während $5^{\prime}$ bis $1 / 2$ Stunde

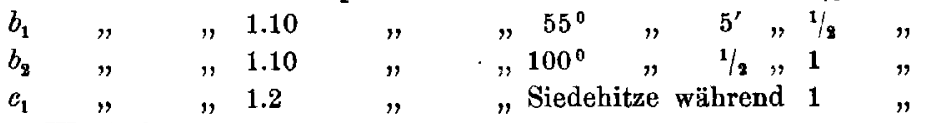

$c_{2}$ Wiederholung von $e_{1}$

$k_{1}$ Natronlauge (oder Kalilauge) von $1.04 \mathrm{sp}$. Gew. bei $55^{\circ}$ während $5^{\prime}$

$k_{2}$ Natronlauge (oder Kalilauge) von $1.04 \mathrm{sp}$. Gew. bei Siedehitze $1 / 2$ Stde.

Die Zeiten sind in den Tabellen genauer angegeben:

Schs. Erhitzung mit konzentrierter Schwefelsäure (5-10 cem) bis die Säure gröfstenteils eingédampft war.

Nach jedem Auszug mit der Säure, wurde die Flüssigkeit so weit mög* lich klar abgehoben, und die Erde während 5 Minuten mit der verdünnten Lauge von $1.04 \mathrm{spez}$. Gew. bei $50^{\circ}$ geschüttelt. Die Kieselsäure nebst der sehr geringen Menge Alaunerde, die dadurch in Losung kam, wurden bestimmt und dem vorhergehenden sauren Auszug zugezählt. Das Volum der kleinen Menge Flüssigkeit, die nach dem Auszug mit verdünnter Lauge noch bei der Erde zurückblieb, wurde annähernd bestimmt.

Die abgehobenen Flüssigkeiten wurden noch zum Überflufs filtriert, und die sehr geringen Mengen Erde, die dabei auf dem Filter zurückblieben, in Rechnung gebracht.

1 Prof. Schroeder van Der Kolk hatte die Güte die mikroskopische Untersuchung des ungelösten Teil der Erden unter seiner Leitung einem seiner Schüler aufzutragen, Herrn J. K. VAN GELDER, Bergbau Kand., nach seiner Methode publiziert in: Kurze Anleitung zur mikroskopiseben Kristallbestimmung. Wiesbaden 1898. Diese Methode beruht auf einer vernünftigen und höchst genauen Bestimmung des Brechungsindex. Ich bringe dem Herm S. v. D. KOLK und besonders dem Herrn vas GELDER meinen verbindlichsten Dank für ihre wertvolle Hilfe. 
Im folgenden wünsche ich einige neuere Untersuchungen und Beobachtungen über die Zusammensetzung und den chemischen Charakter des Verwitterungssilikats mitzuteilen. ${ }^{1}$ Da die oben beschriebene Methode noch keine Nachfolge gefunden hat (ausgenommen im letzten Jahre von Dr. SJOLLEMA), so kann ich nur einzelne selbstgemachte Analysen anführen. Es muls also als Material zur Beantwortung der folgenden H'ragen betrachtet werden:

Ist ein Verbältnis nach chemischen Äquivalenten in einfachen Zahlen oder ein unbestimmtes Verhältnis im Verwitterungssilikat zwischen $\mathrm{SiO}_{2}$ und $\mathrm{Al}_{2} \mathrm{O}_{3}$ anzunehmen? Gibt es also darin verschiedene chemische oder nur unbestimmte Verbindungen von $\mathrm{SiO}_{2}$ mit $\mathrm{Al}_{2} \mathrm{O}_{3}$ ?

Besitzen diese eine bestimmte Löslichkeit in Säuren (Salzsäure, Schwefelsäure) und Alkalien?

Sind alkalinische Basen $\left(\mathrm{CaO}, \mathrm{MgO}, \mathrm{K}_{2} \mathrm{O}, \mathrm{Na}_{2} \mathrm{O}\right)$ im Verwitterungssilikat enthalten?

Inwiefern ist das Eisenoxyd frei, absorptiv oder chemisch gebunden, im Boden?

\section{§ II. Das Verhältnis zwischen $\mathrm{Al}_{2} \mathrm{O}_{3}$ und $\mathrm{SiO}_{2}$.}

\section{A. Alluviale plastische Tone.}

Zur Untersuchung dienten tonreichere und tonärmere Böden, an den Flufsmündungen abgesetzt, also gewöhnliche Alluvialböden, aus den Niederlanden, Jara, Surinam, und Löls aus Limburg. Die folgende Übersichtstabelle I gibt das Verhältnis (in Molek.) an zwischen $\mathrm{SiO}_{2}$ und $\mathrm{Al}_{2} \mathrm{O}_{3}$, wie es in den verschiedenen Auszügen $(a, b, c$ und Schs.) nach den Tab. I-VII (siehe hinten) gefunden ist. Die prozentische Menge $\mathrm{Al}_{2} \mathrm{O}_{3}$, welche gelöst ist und für welche das Verhältnis gilt, ist in der vierten Spalte angegeben. ${ }^{2}$

(S. Tabelle I, S. 269.)

Es ergibt sich daraus deutlich bei diesen Böden, für das V.W., in Salzsäure löslich und für den kaolinischen' in Schwefels. löslichen Teil des V.S.:

${ }^{1}$ Im folgenden benutze ich zur Abkürznng die Buchstaben V.S. für Verwitterungssilikat und U.V.S. für unverwittertes Silikat. Der durch Salzsäure gelöste Teil des Verwitterungssilikats bezeichne ich mit Ss.V.S., den dureh Schwefelsäure gelösten Teil mit Sch.V.S.

2 Da das Mol.-Gew. der Alaunerde 102 ist, so kommen die angegebenen Prozentzahlen fast überein mit den Molekülzahlen, wenn man dieselben mit 100 multipliziert. 
Übersiohtstabelle I.

In Salzsăure löslicb.

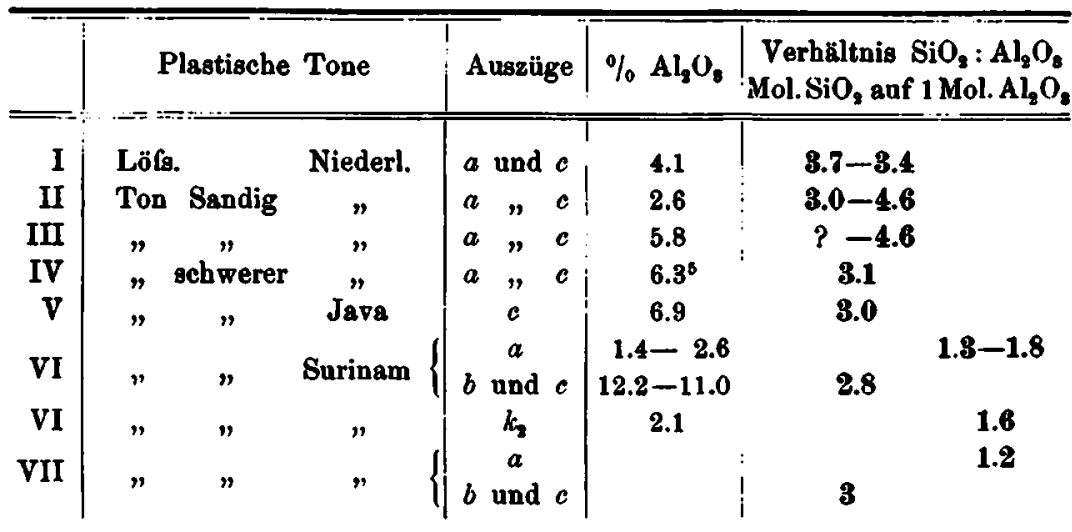

In Schwefelsäure löslich.

\begin{tabular}{|c|c|c|c|c|c|}
\hline & \multicolumn{3}{|c|}{ Plastischer Tone } & Auszüge & $\% \quad \mathrm{Al}_{2} \mathrm{O}_{\mathrm{a}}$ \\
\hline I & Löss. & & Niederl. & 1.7 & 2.0 \\
\hline II & Ton & Leichtere & " & 3.0 & 2.4 \\
\hline III & $n$ & $n$ & $"$ & 5.9 & 2.0 \\
\hline IV & $"$ & Schwerere & $"$ & 5.0 & 2.2 \\
\hline $\mathbf{V}$ & $"$ & " & Java & 4.2 & 2.0 \\
\hline VI & $"$ & $n$ & Surinam & 8.8 & 2.0 \\
\hline VII & $n$ & $n$ & , & 11.7 & 2.0 \\
\hline
\end{tabular}

1. Dafs bei den Ss.V.S. ein einfaches konstantes Verhältnis in $\mathrm{Mol}$. zwischen $\mathrm{SiO}_{2}$ und $\mathrm{Al}_{2} \mathrm{O}_{3}$ nicht vorkommt, sondern von \pm 5 bis \pm 1 variiert.

2. Dafs dieses Verhältnis grölser ist bei sandigen Tonen $(4-5)$ als bei schwereren $( \pm 3)$.

3. Dals im Surinameton ein kleiner Teil $(1-13 \% 2 \%)$ das Verhältnis $\pm 1-1.6$ anweist, welches am leichtesten in Salzsäure und in verdünnter Lauge löslich ist (Auszug $a$ oder $k_{2}$ ). ${ }^{1}$

4. Dafs, mit Ausnahme dieses kleineren Teils, das Ss.V.S. in denselben Boden eine gleichmălsige Zusammensetzung hat, indem $a, b, c_{1}, c_{2}$ dasselbe Verhältnis aufweisen.

1 Wenn bei den Boden (VI und VII) mit verdünnter Salzslüre (a) nur noch wenig $\mathrm{Al}_{2} \mathrm{O}$, gelöst ist, so ist das Verhältnis \pm 1 nnd wăchst, je nachdem mehr $\mathrm{Al}_{2} \mathrm{O}_{8}$ gelöst ist. Wenn $\pm 3 \% \quad \mathrm{Al}_{2} \mathrm{O}_{3}$ gelöst sind, steigt das Verbältnis auf 2.8-8 und bleibt so bei weiterer Lösung von $\mathrm{Al}_{2} \mathrm{O}_{3}$. 
5. Dafs das Verhältnis im Sch.V.S. sich um 2 bewegt.

6. Die unverwitterten Bestandteile bestanden bei allen aus sehr kleinen Partikelchen Kali- und Natronfeldspat und Quarz. Die letzten waren die grölsten.

Die Gleichmäfsigkeit der Zusammensetzung im gröfsten Teil des Ss.V.S. bei diesen Alluvialböden, sowohl in den Niederlanden wie in den Tropen, kann viellejcht damit zusammenhängen, dafs bei allen die Erdteile von dem ursprünglichen Verwitterungsort weit fortgeführt und nach ihrem spez. Gew. abgesetzt sind. In den Niederlanden bestehen die Alluvialböden aus Schlamm, durch die Flüsse auf weitem Wege angefubrt, und das gilt auch wohl für den Alluvialton der Kening (V). Die Tonschicht der Kakaopflanzungen in Surinam ist an den Mündungen der Flusse unter dem Einflufs des Meeres gesunken, denn Diatomeen und Spongiolithen fehlten darin nicht.

\section{B. Böden vulkanischen Uroprungs.}

Padasboden.

Die folgende Bodenart, Padas genannt, welche aus Java stammt und eruptiven Ursprungs ist, bietet ein Beispiel eines Gemisches ron S6.V.S., worin das Verhältnis verschiedene Werte hat.

Der Padas hat denselben Charakter als die sogenannten Eisenockerböden, worin die Bodenteile durch dazwischen abgesetztes Eisenoxyd zementiert sind (Niederländisch: Oerboden). ${ }^{1}$ In dem Niederländischen Diluvium kommt diese Formation vor als eine Oerschicht auf einer geringen Tiefe unter der Oberflăche des Sandbodens. Auf Java kommt sie mitunter in den Gegenden vor, wo der Boden aus eruptiven Massen der Vulkane gebildet ist. Der Padas bildet ein feines Konglomerat, oft so hart, dals er mit dem Spaten gebrochen werden muls. Das Zement, welches den Zusammenhang und die Härte hervorbringt, besteht aus Eisenoxyd und ein sehr basisches Ss.V.S. Der Padas ist nicht plastisch und enthălt nur sehr wenig organische Substanz. Die Analysen kommen vor auf Tab. VIII-X. Aus der Übersichtstabelle II (siebe S. 271) ergibt es sich dentlich, dafs das V.S. ein Gemisch darstellt, worin das Verhăltnis $\mathrm{SiO}_{2}: \mathrm{Al}_{2} \mathrm{O}_{2}$ variiert zwischen 0.3 und \pm 4 .

1 Siehe meine Abhandlung: Uber das Vorkommen, die Znsammensetrung und die Bildung von Eisenanhäufungen in und nnter Mooren. Z. anorg. Chem. 21 (1899), 313. 
Überoichtstabelle II.

\begin{tabular}{|c|c|c|c|c|c|c|}
\hline & \multicolumn{3}{|c|}{ In Salzsäure gelöst } & \multicolumn{2}{|c|}{ In Schwefelsaiure gel. } & \multirow[b]{2}{*}{$\begin{array}{c}\% \\
\text { Ungelöst }\end{array}$} \\
\hline & Auszug & $\% \quad \mathrm{Al}_{8} \mathrm{O}_{4}$ & $\begin{array}{c}\text { Verhältnis } \\
\text { Mol. SiO } \\
\text { auf } 1 \mathrm{Mol} \text {. } \\
\mathrm{Al}_{2} \mathrm{O}_{3}\end{array}$ & $\begin{array}{lll}\% & \mathrm{Al}_{9} \mathrm{O}_{8}\end{array}$ & $\begin{array}{c}\text { Verhältmis } \\
\text { Mol. } \mathrm{SiO}_{2} \\
\text { auf } 1 \mathrm{Mol} \text {. } \\
\mathrm{Al}_{2} \mathrm{O}_{3} \\
\end{array}$ & \\
\hline VIII & $k_{1}$ u. $k_{2}$ & 3.8 & $1.6 ?$ & & & \\
\hline $\begin{array}{l}\text { Braun- } \\
\text { farbig }\end{array}$ & $a, b, c$ & $\begin{array}{l}10.7 \\
14.0 \%\end{array}$ & $3.0-3.8$ & 2.0 & 2.2 & 41.2 \\
\hline IX & $\left(k_{1}\right.$ u. $k_{2}$ & 5.9 & $0.3-0.9$ & & & \\
\hline Hellgelb & $a, b, c$ & $\begin{array}{l}8.9 \\
14.8 \%\end{array}$ & $2.5^{2}$ & 0.3 & & 38.5 \\
\hline $\mathbf{X}$ & $\mid \begin{array}{c}k_{1} \\
a \\
a\end{array}$ & $\begin{array}{l}9.6 \\
7.2\end{array}$ & $\begin{array}{l}0.77 \\
1.8\end{array}$ & 0.9 & 2.2 & 20.2 \\
\hline Rotgelb & $b, c$ & $\begin{array}{l}6.5 \\
23.3 \%\end{array}$ & $2.3^{6}$ & & & \\
\hline
\end{tabular}

Das $\mathrm{SiO}_{2}$-ärmere ist löslich in verdünnter Säure und Lauge. Der braunfarbige (VIII) enthält die kleinste, der rotgelbe (X) die gröfste Menge $\mathrm{SiO}_{3}$-armes V.S. Die Verwitterung ist am stärksten in IX fortgeschritten. ${ }^{1}$ Im O.V.S. finden wir neben Albit und anderen Feldspaten (Quarz fehlt) viel kristallinische, basische Silikate: Augit,

VIII enth\&̆lt $41 \%$ ungelöstes in Salzsăure und Schwefelsăure, $\mathrm{X}$ nur $20 \%$. In VIII wächst das Verbaltnis in den Auszügen $a-c$ von 3-3.8. In IX wächst es in den Auszïgen $k$ von $0.3-0.9$ und in den Auszügen $a-c$ ist eg ziemlich konstant. In $X$ ist es zuerst in $k$ ziemlich konstant 0.77 , und wächst dann in $a-c$ von 1.8-2.35. In VIII ist ganz abweichend im ersten Extrakt $k_{1}$ (5 Minuten) das Verhaltmis $\mathbf{8 . 0}$ gefunden, indem jedoch nur $0.5 \% \quad \mathrm{Al}_{8} \mathrm{O}_{8}$ gelöst war. Eine zweite Bestimmung in $5 \mathrm{~g}$ Erde ergab 2.6. Ich habe mich abgefragt, ob hier vielleicht eine Abscheidung rom löslichen $\mathrm{SiO}_{2}$ im Spiele war. Auf Java wird diese Erscheinung oft auf Sawab-Feldern beobachtet, wie Kramras mitgeteilt hat (Mededeelingen ran bet Proef Station Oost Java, Nr. 49, [1893]). Wenn sie nach der Berieselung wieder in der Trockenzeit Risse bekommen, zeigen sie ein beschimmeltes Ansehen; namentlich in den Gossen der Zuckerrohrgarten bilden sich sehr dünne Krusten, worin organische Substanz, Gips, uud viel freie Kieselsäure erkennbar war. Auch der Boden eines derartigen Gartens gab mit Wasser eine Lösung, die neben organischer Substanz und Alkalisalzen freie $\mathrm{SiO}_{2}$ enthielt. Bei ejner Verwitterung, welche ein so $\mathrm{SiO}_{2}$-armes Produkt liefert, als im Padas vorkommt (Ausailge $k$ ), whire es nicht fremd, dafs lösliche Kieselsäure im Boden nachzuweisen ist. Man bedenke doch, dafs die Verwitterung in diesen vulkanischen Eruptivmaseen viel starker ist als in den gewöhnlichen Alluvialtoneu. Eine näbere Untersuchung wäre sehr wünschenswert. 
Hypersten, Andesit, welche zu $\mathrm{SiO}_{2}$-armer Alaunerde verwittern können. Der kaolinartige Teil des V.S. ist gering, namentlich im hellgelben Padas.

Vulkanische Böden aus Java und Sumatra.

Sie sind vulkanischen Ursprungs und liegen in der Nähe von noch wirksamen Vulkanen. Das U.V.S. enthält denn auch Bestandteile einer vulkanischen Asche. ${ }^{1}$

Übersichtstabelle III.

\begin{tabular}{|c|c|c|c|c|c|}
\hline & \multirow{2}{*}{ Aus- } & \multicolumn{2}{|c|}{ In Salzsäure gelöst } & \multicolumn{2}{|c|}{ In Schwefelsäure gel. } \\
\hline & & $\begin{array}{c}\% \mathrm{Al}_{2} \mathrm{O}_{3} \\
\text { gelöst }\end{array}$ & $\begin{array}{c}\text { Verhältnis } \\
\text { Mol. } \mathrm{SiO}_{2} \\
\text { auf } 1 \mathrm{Mol} \text {. } \\
\mathrm{Al}_{2} \mathrm{O}_{3}\end{array}$ & $\begin{array}{c}\% \mathrm{Al}_{2} \mathrm{O}_{3} \\
\text { gelöst }\end{array}$ & $\begin{array}{c}\text { Verhältnis } \\
\text { Mol. } \mathrm{SiO}_{2} \\
\text { auf } 1 \mathrm{Mol} \text {. } \\
\mathrm{Al}_{2} \mathrm{O}_{3}\end{array}$ \\
\hline \multirow{3}{*}{$\begin{array}{l}\text { XI A Gondang Legie } \\
\text { XII Rotbraun-Deli }\end{array}$} & $c$ & 17.3 & 2.2 & $0.2^{8}$ & 3.6 \\
\hline & $a, b$ & 12.5 & 0.9 & $1.2^{8}$ & 3.2 \\
\hline & e & \begin{tabular}{|r}
12.8 \\
\\
\end{tabular} 25.3 & 2.2 & & \\
\hline \multirow[t]{2}{*}{ XIII Grau-Deli } & $a$ & 2.9 & 2.1 & 2.0 & 4.0 \\
\hline & $c$ & $\begin{array}{ll}7.9 & \\
& 10.8\end{array}$ & 2.7 & & \\
\hline
\end{tabular}

Diese Erden enthalten viel Ss.V.S. Das Verhältnis für die ganze Menge in Salzsäure gelöstes $\mathrm{Al}_{2} \mathrm{O}_{3}$ ist bei XI und XIII $\pm \mathbf{2 . 2 - 2 . 7}$. Der löslichste Teil des V.S. ist jedoch namentlich für XII noch basischer und löslicher, wo die Hälfte, sowohl in $a$ wie in $b$, das Verhältnis 0.9 besitzt. Wir müssen hier konstatieren, dals das Verhältnis 0.9 bei XII konstant ist, weil es in $a$ und $b$ dasselbe ist. Die zweite Hälfte des Ss.V.S. in XII hat auch das Verhältnis 2.2. Wir kommen unten darauf zurück (S. 281).

Ein kaolinischer Teil mit dem Verhältnis $\pm \mathbf{2}$ fehlt. Was Schwefelsäure löst, hat das Verhältnis 3-4. Die Erde XII ist gar nicht plastisch, XI nur wenig, XIII merkbar.

Ich mache hier aufmerksam darauf, dafs das Verhältnis \pm 2 sowohl im Ss.V.S. bei diesen Böden, wie im Sch.V.S. der gewöhnlichen Tonböden vorkommt, ohne dals wir die Differenz in ihren Eigenschaften erklären können.

1 Sanidinfeldspat (mit Glaseinschlüssen), Augit, jungeruptiv-dichroitische dunkelgrüne Hornblende. Grörse der Körner 0.5-3 Mikrons, einzelne 1 bis $2 \mathrm{~mm}$. Viel Magnetit: in XI $3.2 \%$; in XII $4.3 \%$; in XIII $0.9 \%$. 


\section{Lateritböden.}

Diese Bodenart ist immer bezeichnend für die Tropen gehalten. Wie im Anfang mitgeteilt, ist früher wohl bemerkt, dafs sie meistenteils sehr eisenreich war, aber nicht, dais sie ein $\mathrm{SiO}_{2}$-armes V.S. enthielt. Nur ihr hoher Eisengehalt ist für den Laterit charakteristisch gehalten. Erst BAUER hat in 1898 gefunden, dafs im Laterit der Seychelleninseln, welchen Dr. Bauer dort entdeckt und gesammelt hat, kristallinischer Hydragillit vorkommt, und es beschrieben als ein feinschuppiges Aggregat winziger, ziemlich stark doppeltbrechender Täfelchen und Plättchen. Querdurchschnitte derselben zeigten sich als sehr schmale Leistchen. Aus einer Bauschanalyse leitete er die Formel $\mathrm{Al}_{2} \mathrm{O}_{3} \cdot 3 \mathrm{H}_{2} \mathrm{O}$ ab. Die Kieselsäure war hauptsächlich Quarz. Mehr oder weniger Eisenoxyd war in den Spalten und Höhlen des Aggregats abgesetzt. ${ }^{1}$ Auch G. C. DuBors hat in 1903 in primären und sekundären Lateriten neben Eisenoxyd viel Alaunerde gefunden, in dem die Kieselsäure grölstenteils als Quarz anwesend war. ${ }^{2}$ Beide nehmen also an, dals der Laterit entstanden ist durch einen Verwitterungsprozefs, wobei die Kieselsäure in gröiserer Menge verschwunden ist als der gewöhnliche Tonbildung entspricht, ja selbst ganz verschwinden kann wie es im Laterit der Seychellen-Inseln der Fall ist. Diese Verwitterung hat also den Charakter einer Tendenz zur Umwandlung der Silikate in reine Alaunerde.

Die Zusammensetzung des V.S. in sieben Lateriten ist in der folgenden Tabelle übersichtlich zusammengestellt. (Siehe die Analysen auf den Tabellen XIV-XX). ${ }^{3}$

(S. Tabelle IV, S. 274.)

Diese Analysen lehren, dals der weit fortgeschrittene Grad der Verwitterung, also der geringe $\mathrm{SiO}_{2}$-gehalt des V.S. in der ersten Stelle den Laterit charakterisiert. Das Eisenoxyd kommt nur in der

${ }^{1}$ M. BaUtr, Beiträge zur Geologie der Seychellen-Inseln, und besonders zur Kenntnis der Laterite. Neues Jabrbuch für Mineralogie u. s. w. (1898), Bd. II, S. 168.

2 G. C. Dubors, Laterit. Tschermaks Mineral. und Petrogr. Mitteilungen 22, $1-161$.

${ }^{5}$ Den Laterit der S.-Inseln habe ich noch einmal ausführlich analysiert, um die Menge gebundener Kieselsäure genau zu bestimmen, und die Löslichkeit der Alaunerde mit der Löslichkeit des Minerals Hydrargillit zu vergleichen. Ich sage Herrn Baugr freundlich Dank für die Proben, die er mir gütigst zugeschickt hat. 
Übersichtstabelle IV.

\begin{tabular}{|c|c|c|c|c|c|}
\hline $\mathrm{Nr}$. & Anszug & $\begin{array}{c}\% \mathrm{Al}_{2} \mathrm{O}_{8} \\
\text { gelöst }\end{array}$ & $\begin{array}{c}\text { Verhältnis } \\
\text { Mol. } \mathrm{SiO}_{2} \\
\text { auf } 1 \mathrm{Mol} . \mathrm{Al}_{2} \mathrm{O}_{\mathrm{B}}\end{array}$ & $\mathrm{Fe}_{2} \mathrm{O}_{3}$ & $\begin{array}{l}\text { \% Ungelöst } \\
\text { nach Salzs. } \\
\text { u. Sehwefels. }\end{array}$ \\
\hline XIV & $k_{2}$ & 8.6 & 0.3 & & \\
\hline Pla- & $a-c$ & 16.4 & $1.2-1.6$ & 3.8 & 16.8 \\
\hline stisch & Sch. & $10.9 \quad 34.9$ & 1.6 & & \\
\hline $\mathrm{XV}$ & $\begin{array}{c}k_{1}, k_{2} \\
b, c_{1}, c_{2} \\
\text { Sch. }\end{array}$ & $\begin{array}{c}1.5 \text { u. } \\
16.1 \\
5.9\end{array}$ & $\begin{array}{c}1.4-2.0 \\
1.6-1.4 \\
1.7^{6}\end{array}$ & 17.8 & 10.5 \\
\hline XVI & $\begin{array}{c}k_{1}, k_{9} \\
b, c \\
\text { Seh. }\end{array}$ & $\begin{array}{r}11.0 \\
12.2 \\
3.3\end{array}$ & $\begin{array}{cc}0.3-0.4 & \\
& 1.6 \\
& 1.7^{7}\end{array}$ & 11.6 & 28.9 \\
\hline XVII & $\begin{array}{l}k_{1}, k_{2} \\
b \\
c, \text { Sch. }\end{array}$ & $\begin{array}{c}1.0 \text { u. } 3.2 \\
7.3 \\
\text { n. bestimmt }\end{array}$ & $\begin{array}{ll} & 1.1-1.7\end{array}$ & $\begin{array}{l}42.9 \\
\text { n. b. }\end{array}$ & \\
\hline XVIII & $\begin{array}{c}k_{1}, k_{\mathrm{z}} \\
a-c\end{array}$ & $\begin{array}{l}18.3 \\
12.1\end{array}$ & $\begin{array}{l}0.2^{7} \\
0.6\end{array}$ & $35^{\circ}$ & 3.1 \\
\hline & & Von den & Seychellen Inseln. & & \\
\hline XIX & $k_{1}, a-c$ & 42.6 & $0.03-0.1$ & 27 & 3.8 \\
\hline $\mathbf{X X}$ & $\begin{array}{l}a, k_{1} \\
b, c\end{array}$ & $\begin{array}{r}22.6 \\
3.1\end{array}$ & $0.8-1$ & $3^{8}$ & $\begin{array}{l}53.7 \\
\text { Quarz }\end{array}$ \\
\hline
\end{tabular}

zweiten Stelle, und ist die Folge davon, dafs in den meisten Fällen, das ursprüngliche verwitterte Gestein reich an eisenhaltigen Silikaten gewesen ist.

In allen ist der unverwitterte Teil gering, ausgenommen, wenn viel Quarz anwesend ist (wie in XVI und XX). Die Menge leichtlöslicher V.S. ist grofs, und die Verhältniszahlen wechseln darin $z$ wischen 0 und \pm 1 . Im schwerlöslichen und geringeren Teil wechseln sie bis 1.6. Merkwürdig ist es, dafs der durch Schwefelsäure zersetzbare (kaolinische) Teil des V.S. fehlt (wie in XVIII bis $\mathrm{XX}$ ) oder kein höheres Verhältnis zeigt als 1.6, wie in XIV. Das U.V.S. besteht grörsenteils aus kristallinischen basischen Silikaten, doch fehlen dabei Feldspat uud Quarz nicht ganz (Siehe die Angaben auf Tab. XIV-XVIII. Es ist nun die Frage, inwiefern kristallinisches Aluminiumoxydtrihydrat $\left(\mathrm{Al}_{2} \mathrm{O}_{3} \cdot 3 \mathrm{H}_{2} \mathrm{O}\right)$ neben amorpher, $\mathrm{SiO}_{2}$-haltiger Alaunerde oder eine amorphe, wasserhaltige Alaun. erde, oder ein Gemisch von beiden, im Laterit vorkommt. Kristallinisches Hydrargillit ist mikroskopisch nur in XVIII, aufser in XIX und $\mathrm{XX}$ beobachtet. 
Um diese Frage zu lösen, müssen die Eigenschaften und der Wassergehalt der Erde mit denen des kristallinischen Hydrats und des kolloidalen (amorphen) Hydrogels von $\mathrm{Al}_{2} \mathrm{O}_{3}$ verglichen werden.

Aus der kalischen Lösung von $\mathrm{Al}_{2} \mathrm{O}_{3}$ scheidet sich durch Einwirkung von $\mathrm{CO}_{2}$ ein mikrokristallinisches Hydrat ab, das genau der Formel $\mathrm{Al}_{2} \mathrm{O}_{3} .3 \mathrm{H}_{2} \mathrm{O}$ entspricht und unabhängig ist von Wasserdampfdruck und Temperatur innerhalb gewissen (weiten) Grenzen. Erst bei $170^{\circ}$ fängt es an Wasser zu verlieren und wird dabei amorph. ${ }^{1}$

Der amorphe Hydrogel von $\mathrm{Al}_{2} \mathrm{O}_{3}$ dagegen ist in seinem Wassergehalt kontinuierlich abhängig rom Wasserdampfdruck und der Temperatur, ${ }^{2}$ und von seiner Vergangenheit ${ }^{3}$. Er ist keine chemische Verbindung von $\mathrm{Al}_{2} \mathrm{O}_{3}$ mit $\mathrm{H}_{2} \mathrm{O}$, sondern eine Absorptionsverbindung im unbestimmten Verhältnis.

Das kristallinische Hydrargillit $\left(\mathrm{Al}_{2} \mathrm{O}_{3} \cdot 3 \mathrm{H}_{2} \mathrm{O}\right)$, wie es als Mineral in der Natur vorkommt," wird beschrieben als schwer löslich in Säuren, selbst bei Erwärmung. Das Wasser beträgt genau 3 Molek.,

1 Den Beweis gab ich schon vor längerer Zeit. Reeueil trav. chim. PaysBas 7 (1888), 76 .

Frisch bereitet

Luft trocken $15^{\circ}$

Schwefels. trock. $15^{\circ}$

bei $100^{\circ}$

$140^{\circ}$

$160^{\circ}$

$180^{\circ}$

$200^{\circ}$

$250^{\circ}$

$300^{\circ}$
Wassergehalt in Molekülen auf $1 \mathrm{Mol}$. $\mathrm{Al}_{2} \mathrm{O}_{3}$ :

Hydrogel aus Hydrogel nach einer sehr verdünnt. 6 Monaten unter Lösg. abgeschieden $6-4.5$

2.6

2.2

1.9

1.8

-

1.6

1.2

0.9
Wasser

4.4

$2.9^{5}$

2.9

2.7

2.6

$-$

$-$

$0.9^{5}$
Hydrat kristall. aus e. alkal Lsg. durch $\mathrm{CO}_{2}$ abgesch.

3.0

3.0

3.0

3.0

3.0

2.7

2.2

Wenn der Hydrogel 6 Monate unter Wasser gestanden hat, scheint er gröfstenteils in eine chemische Verbindung übergegangen zu sein.

s d. h. die Art der Bereitung, die Modifikationen, die er durch die Zeit (Alter), Temperaturänderungen, Einflufs von verschiedenen Agentien (z. B. Wasser) in seinem Bau erfahren hat, also seine ganze Geschichte.

4 Wird besehrieben als sehr feinkörnige Aggregate blätteriger Struktur; die einzelnen Blättchen sind von geringer Abmessung, geordnet meistenteils in Rosettenform oder als Sphärolithen. Die Blättchen sind sehwach, doppeltbrechend, wenn der Habitus blätterig, stark, wenn er faserig ist.

Der Diaspor $\mathrm{Al}_{2} \mathrm{O}_{3} \cdot \mathrm{H}_{2} \mathrm{O}$ ist unlöslich in Säuren; wie gewöhnlich ist ein niedrigeres Hydrat eines Oxyds weniger löslich oder viel unlöslicher als ein höheres. 
ist chemisch gebunden und wird erst bei höherer Temperatur ausgetrieben. Der Brechungsindex des Minerals ist nach der letzten Bestimmung von SCHROEDER VAN DER KoLK 1.57. ${ }^{1}$ Ich habe untersucht 1. Mineral aus Langesund (Norwegen), und 2. von Onro Pieto (Brazil) Minas Geraes. Aus den ersten konnten einzelne Kristallchen, feine Blättchen, losgemacht werden. Diese konnten mit Salzsäure einige Zeit erhitzt werden, ohne dafs sie sich merkbar lösten. Das zweite war von massiv-kristallinischer Struktur. Von dem feingeriebenen Pulver wurde gelöst bei Erhitzung während 1/4 Stunde:

Durch verdünnte und starke Salzsäure.
I. $40 \%$ (keine $\mathrm{SiO}_{2}$ )
II. $70 \%(, ")$
$10 \%$ (Spur $\mathrm{SiO}_{2}$ )
$24 \%\left(3 \% \quad \mathrm{SiO}_{2}\right)$.

Durch verdünnte Kalilösung.

Es ist also nicht unlöslich, weder in Salzsäure, noch in verdünntem Kali, doch hängt die Lösungsgeschwindigkeit viel von dem Verteilungsgrad ab.

$\nabla$ on einer amorphen Verbindung (oder Komplex) zwischen $\mathrm{SiO}_{2}$ und $\mathrm{Al}_{2} \mathrm{O}_{3}$ in den Böden kann man Eigenschaften erwarten, die mehr oder weniger analog sind denjenigen eines Mischhydrogels, wie solche entstehen, wenn ein Gemisch der Hydrosols von $\mathrm{Al}_{2} \mathrm{O}_{3}$ und $\mathrm{SiO}_{2}$ koaguliert, ${ }^{2}$ nämlich 1. dals die Absorptions-Verbindung einen unbestimmten Wassergehalt hat, 2. dals dieser Gehalt kontinuierlich von $T$ und $p$ abhängt, und das Wasser also mit sehr verschiedener Stärke gebunden ist, ${ }^{3}$ 3. dafs es eine Löslichkeit besitzt,

1 Nach einer schriftlichen Mitteilung von Prof. Schrogder vas der Kolk, der auf meine Bitte den Brechungsindex aufs neue bestimmt hat. Die Zabl von Rosenbusch, 1.535 , ist also zu niedrig.

${ }^{2}$ Über die Misch-Hydrogels, siehe meine 6. Abhandlung $Z$. anorg. Chem. $23(1900), 333$.

${ }^{3}$ Die Wasserbestimmung des schwächer und stärker gebundenen Wassers war also wichtig. Bei den untersuchten Laterit- und Padasarten ist der Gehalt an organischer Substanz nur sehr gering, so dafs der Glühverlust ohne grofsen Fehler auf Rechnung des Wassers gestellt werden kann. Für die übrigen Böden war die Bestimmung des stärker gebundenen Wassers (über eine Temperatur von $100^{\circ}$ ausgetrieben) möglich durch die Bestimmung des Humusgehaltes nach der Methode beschrieben in meiner Abhandlung $L$. V.St. 37 (1890), 283. Unter schwächer gebundenes Wasser verstehe ich das Wasser bei $15^{\circ}$ über Schwefelsäure abgegeben, und das bei $100^{\circ}$ ausgetrieben. Man muls dies natürlich so verstehen, dafs allerlei Grade der Stärke vorkommen, dal's also das Wasser in kolloidalen Substanzen um so stärker gebunden ist, je nachdem weniger absorbiert ist, und umgekehrt um so schwächer, je nachdem mehr absorbiert wird. Bei kristallinischen Substanzen ist die Stärke der Bindung eine konstante. 
die von ihrer Zusammensetzung abhängig ist. Es hat sich auch schon oben ergeben, dals es um so leichter löslich war in verdünnter Säure und Lauge, je nachdem weniger $\mathrm{SiO}_{2}$ mit dem amorphen $\mathrm{Al}_{2} \mathrm{O}_{3}$ verbunden war.

Wenn nun Hydrargillit im Boden anwesend ist, so muls er mikroskopisch zu beobachten sein, über Schwefelsäure kein Wasser verlieren, eine Erhitzung bis $180^{\circ}$ ertragen und genau $3 \mathrm{Mol} . \mathrm{H}_{2} \mathrm{O}$ enthalten. Das hat sich nun alles bewährt bei dem Laterit der Seychelleninseln. BAUER hat es zuerst mikroskopisch beobachtet und beschrieben (siehe oben S. 266). Meine Analysen bestätigen, dals die Alaunerde so gut als ganz Hydrargillit mit $3 \mathrm{H}_{2} \mathrm{O}$ anwesend ist, wenn ich annehme, dals das $\mathrm{Fe}_{2} \mathrm{O}_{3}$ ungefähr $1 \mathrm{Mol}^{\mathrm{H}} \mathrm{H}_{2} \mathrm{O}$ gebunden hält. ${ }^{1}$

Das ergibt sich aus der folgenden Berechnung:

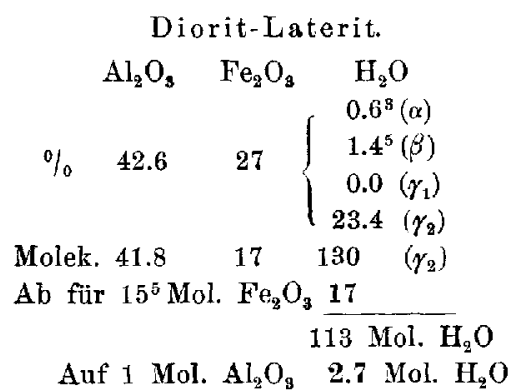

$$
\begin{aligned}
& \text { Granit-Laterit } \\
& \mathrm{Al}_{2} \mathrm{O}_{3} \quad \mathrm{Fe}_{2} \mathrm{O}_{3} \quad \mathrm{H}_{2} \mathrm{O} \\
& \% \quad 26 \quad 3.8\left\{\begin{array}{c}
0.3^{6}(\alpha) \\
0.6^{4}(\beta) \\
0.0\left(\gamma_{1}\right) \\
12.9^{6}\left(\gamma_{2}\right)
\end{array}\right. \\
& \begin{array}{llll}
\text { Molek. 25.5 } & 2.4 & 72 & \left(\gamma_{2}\right)
\end{array} \\
& \mathrm{Ab} \text { für } 2.4 \mathrm{Mol}_{\mathrm{Fe}} \mathrm{O}_{3} \quad 2^{4} \\
& \begin{array}{ll} 
& 69^{6} \mathrm{Mol} . \mathrm{H}_{2} \mathrm{O} \\
\text { Anf } 1 \mathrm{Mol} . \mathrm{Al}_{2} \mathrm{O}_{3} & \mathbf{2 . 7 ^ { 6 }} \mathrm{Mol} . \mathrm{H}_{2} \mathrm{O}
\end{array}
\end{aligned}
$$

Also ist die Menge Wasser, die über Schwefelsäure $(\alpha)$ und bei $100^{\circ}(\beta)$ ausgetrieben wird, sehr klein; bei $180^{\circ}\left(\gamma_{1}\right)$ null, und bei höherer Hitze anvähernd $3 \mathrm{Mol} . \mathrm{H}_{2} \mathrm{O}$ auf jedes $\mathrm{Mol}$. $\mathrm{Al}_{2} \mathrm{O}_{3}\left(\gamma_{2}\right)$.

Die Ungewifsheit, wie viel Wasser im Eisenoxyd gebunden ist, und ein sehr geringer Gehalt an organischer Substanz macht die Zahl 2.7 bis 2.8 etwas unsicher. Dals jedoch eine kleine Menge amorpher $\mathrm{SiO}_{2}$-haltiger Alaunerde anwesend ist, ist darum annehmlich, weil 1.3 und $2.3 \%$ gebundener $\mathrm{SiO}_{2}$ gefunden sind und weil über Schwefelsäure und bei $100^{\circ}$ etwas Wasser ausgetrieben ist. Der Granit-Laterit enthält $3 \% \quad \mathrm{Al}_{2} \mathrm{O}_{3}$ mit dem Verhältnis $\pm 1 \mathrm{Mol}$. $\mathrm{SiO}_{2}$. (Siehe die vier letzten Auszüge Tabelle XX). Eine gewisse Menge kristallinische Diaspor nehme ich hier nicht an, wieBADER in allen Fällen tut, wo der Wassergehalt unzureichend ist für die Menge Alaunerde, denn erstens besteht für die Bildung von Diaspor neben Hydrargillit

${ }^{2}$ In Übereinstimmung mit der auf S. 297 varkommenden Betrachtung über den Wassergehalt des Eisenoxyds im Boden. 
noch kein Beweis, 2. ist Diaspor unlöslich in Säuren, 3. war es BADER noch unbekannt, dafs neben kristallinischem Hydrargillit amorphe Verbindungen von Alaunerde mit unbestimmten Mengen $\mathrm{SiO}_{2}$ und $\mathrm{H}_{2} \mathrm{O}$ vorkommen.

Was die Löslichkeit des Hydrargillits in diesen Lateriten anbetrifft, konnte verdünnte Lauge schon in einer halben Stunde bei $60^{\circ}$ reichlich die Hälfte des Gehalts in Lösung bringen. ${ }^{1}$

Die Löslichkeit ist also viel gröfser (geschwinder) als die des Minerals, doch glaube ich, dafs die mikroskopischen Abmessungen der Kristalle davon die Ursache sind.

Dieselbe Berechnung auf den Laterit XVIII, worin kristallinischer Hydrargillit beobachtet ist, anwendend, bekommt man:

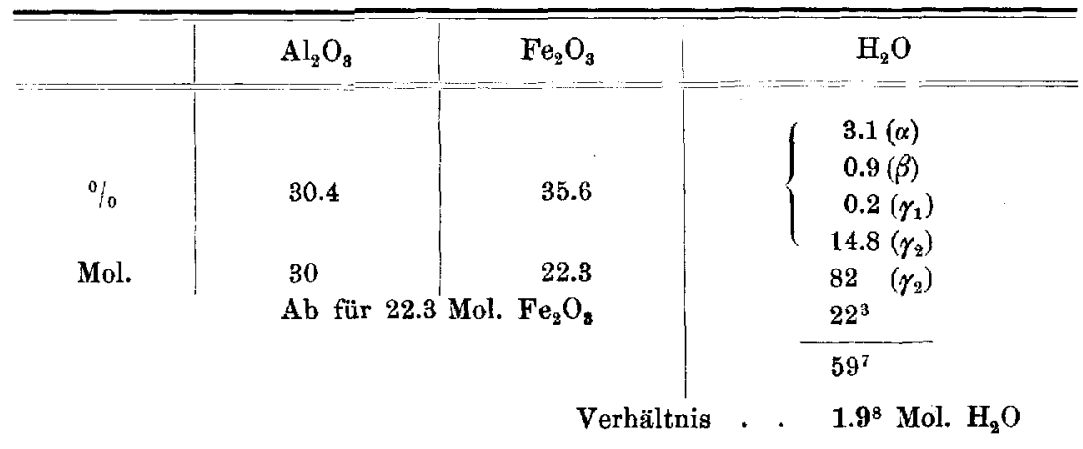

Selbst wenn man das Eisenoxyd anhydrisch annimmt, ist das Verhältnis noch nicht 3. Nur ein Teil der Alaunerde kann also kristallinisches Hydrargillit sein. Die Erde enthält dann auch $\pm 8 \%$ lösliche $\mathrm{SiO}_{2}$ und eine Menge von $4-6 \% \mathrm{Al}_{2} \mathrm{O}_{3}$ mit dem Verbältnis $\pm \mathbf{0 . 8}$ - $\pm \mathbf{1 . 1}$. Als sie mit verdünnter Salzsäure ausgezogen war, um die gröfste Menge $\mathrm{Fe}_{2} \mathrm{O}_{3}$ zu entfernen, zeigte sich unter dem Mikroskop ein Aggregat von Faserchen und Schüppchen, deren Brechungsindex durch Herrn VAN GELDER bestimmt wurde zwischen 1.56 und 1.59 (näher an 1.56).

Die Erde enthält also ein Gemisch von viel Hydrargillit mit $\mathrm{SiO}_{2}$-armer Alaunerde, die weniger als $3 \mathrm{Mol} . \mathrm{H}_{2} \mathrm{O}$ enthält.

Dieselbe Berechnnng ergibt für den eisenreichen Laterit XVIII ein Verhältnis zwischen 2.5 und $\mathbf{3}$.

1 Diorit-Laterit enthält $42 \% \mathrm{Al}_{2} \mathrm{O}_{3}$. Gelöst durch Lauge $\left(k_{2}\right) 24 \%$. Granit-Laterit enthält $26 \% \mathrm{Al}_{2} \mathrm{O}_{3}$. Gelöst durch Salzsäure (a) $7.4 \%$ und danach durch Lauge $\left(k_{1}\right) 15.3 \%$. 
Doch macht der hohe Eisengehalt $(43 \%)$ diese Berechnung etwas zu unsicher, weil das dafür berechnete Wasser die Verhältniszahl zu viel drückt. Für den plastischen Laterit XIV ist die Berechnung unzuverlässig, obgleich das Eisenoxyd gering und der Gehalt an $\mathrm{Al}_{2} \mathrm{O}_{3}$ mit nur $0.3 \mathrm{SiO}_{2}$ bedeutend ist, denn er enthält noch sehr viel $\mathrm{Al}_{2} \mathrm{O}_{3}$ mit den Verh.-Zahlen 1.2 bis 1.6. Man kann nur schliefsen, dals diese letzte Menge V.S. nicht über $2 \mathrm{Mol} \mathrm{H}_{2} \mathrm{O}$ enthalten kann. ${ }^{1}$ Anch andere Laterite, die früher (obgleich unvollständig) analysiert sind, ergeben einen zu niedrigen Wassergehalt. ${ }^{2}$

In den Deliböden XII und XIII kommt wohl kein Hydrargillit vor, denn die ersten Auszüge (a) geben die Verh,-Zahlen $\mathbf{0 . 9}$ und 2.1. In den drei Padasarten könnte nur die Sprache davon sein bei dem hellgelben (IX), wo $4 \% \mathrm{Al}_{2} \mathrm{O}_{3}$ mit der Verh.-Zahl 0.3 im ersten Auszug gelöst wurde.

Aus diesen Berechnungen und einigen von Bader und DuBors mitgeteilten Analysen scheint es mir annehmlich, dals die Laterite welche zu wenig Wasser enthalten, um für die Alaunerde $3 \mathrm{Mol}$. $\mathrm{H}_{2} \mathrm{O}$ zu berechnen, neben wenig Hydrargillit amorphe $\mathrm{SiO}_{2}$-ärmere

' Die Berechnung für XIV ist:

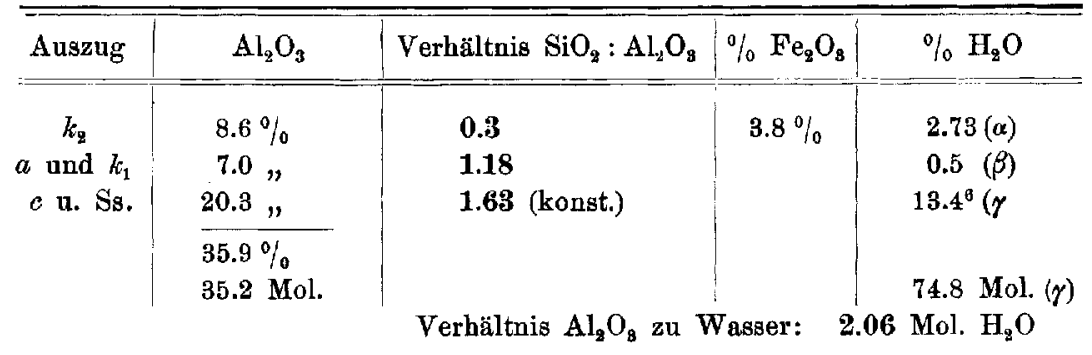

${ }^{2}$ Z. B. der sekundäre Laterit der Fregatteninsel, ein laterisierter Sandstein (BADER). Er enthält nur wenig $\mathrm{Fe}_{2} \mathrm{O}_{3}\left(3.1 \%\right.$ ), wenig lösliches $\mathrm{SiO}_{2}$, und doch berechne ich nur eine V. Zahl von $1.66 \mathrm{H}_{2} \mathrm{O}$. Ebenso für den Laterit von Rangoon (BAUER) 1.6. Der diabasische primäre Oberfläehe-Laterit (Duвогs) ergibt 1.4, wenn für das Eisenoxyd (56\%) $1 \mathrm{Mol}^{\mathrm{H}} \mathrm{H}_{2} \mathrm{O}$ in Rechnung gebracht wird, 2.4 wenn $1 / 2$ Mol. $\mathrm{H}_{2} \mathrm{O}$ in Rechnung gebracht wird. Der diabasische primäre Tiefe-Laterit (DøBoIs) ergibt unter denselben Annahmen 1.7 nnd 2.0 $\mathrm{H}_{2} \mathrm{O}$. Bauxite geben zwar oft \pm 3 (bei Giessen, Garbenteich und Grube Firnewald), aber auch 2.2 (bei Wochein) und 1.2 (Allauch bei Marseille) nach BaUkrs Angaben, S. 139 u. 142 von mir berechnet.

Bei diesen Berechnungen mufs man in Betracht nehmen, dals die angegebenen Mengen Wasser wohl etwas zu hoch sind, weil nicht bestimmt war, wieviel Wasser bei $100-170^{\circ}$ entwichen war. Dieses Wasser gehörte nicht zum Hydrargillit. 
Alaunerde enthalten, jedoch keinen kristallinischen Diaspor, wie BAUER annimmt.

Der kristallinische Hydrargillit, der ganz frei von $\mathrm{SiO}_{2}$ und ganz rein ist, scheint mir nicht allein ein Endprodukt der Verwitterung zu sein, sondern auch eine letzte Umbildung einer amorphen Substanz in eine kristallinische, wobei $3 \mathrm{Mol} . \mathrm{H}_{2} \mathrm{O}$ Wasser chemisch gebunden werden. Denn die noch $\mathrm{SiO}_{2}$-haltende Alaunerde, die nehen dem Hydrargillit gefunden wird, enthält weniger als 3 Mol. $\mathrm{H}_{2} \mathrm{O}$ und ist amorph. Dais der Hydrargillit, auch auf primärer Lagerstätte, noch die ursprüngliche Struktur des Silikats zeigt, woraus er duch Verwitterung entstanden ist, macht doch wohl keine Beschwerde gegen diese Umbildung. Denn diese kristallinischen Teilchen sind winzig klein und ihre Anhäufung kann also noch die Pseudostruktur des Silikats zeigen. Daneben kommen auch gut ausgebildete Kristalle vor. BADER erwähnt, dafs solche beobachtet sind in kleinen Höhlen im Bauxit. ${ }^{1}$ So habe ich auch gut ausgebildete Kristalle von farblosem Vivianit in Höhlen von Raseneisenstein mit mikrokristallinischem Siderit $\left(\mathrm{FeCO}_{3}\right)$ beobachtet, ${ }^{2}$ welche als letzte oder Endbildungen aus amorphen Eisenanhäufungen zu betrachten sind. Eisenglanz, Roteisenstein können unter Umständen verwittern, Wasser aufnehmen und Brauneisenstein bilden; wie auch umgekehrt unter anderen Umständen Nadeleisenerz (Göthit) Wasser verlieren und in Roteisenstein übergehen kann. Es ist natürlich möglich, dals es Umstände gibt, wobei der kristallinische Hydrargillit wieder Hydratwasser verliert und in kristallinischen Diaspor übergeht $\left(\mathrm{Al}_{2} \mathrm{O}_{3} \cdot \mathrm{H}_{3} \mathrm{O}\right)$. Doch kommt es mir vor, dals bis jetzt kein einzelner Beweis gefunden ist, dals erst kristallinischer Diaspor nnd danach kristallinischer Hydrargillit gebildet ist, oder beide zu gleicher Zeit, oder Hydrargillit aus Diaspor. Wenn zu wenig Wasser für die Formel $\mathrm{Al}_{2} \mathrm{O}_{3} \cdot 3 \mathrm{H}_{2} \mathrm{O}$ gefunden wurde, dann löste sich auch noch $\mathrm{SiO}_{2}$ mit der $\mathrm{Al}_{2} \mathrm{O}_{3}$ und war diese $\mathrm{SiO}_{2}$-arme Alaunerde auch amorph. Hat es also nicht grolse Wahrscheinlichkeit, dafs das Entstehen des kristallinischen Hydrargillits aus dem amorphen Verwitterungsprodukte, sobald alle $\mathrm{SiO}_{2}$ daraus verschwunden ist, eine letzte Phase im Prozels, eine kristallinische Umbildung ist?

Es sei mir erlaubt, die Bemerkung zu machen, dafs in der

1 Durch Liebreich im Bauxit von Vogelsberg bei Giessen; durch Petersen im Bauxit von Rüdigheim (BAUER S. 138.).

2 Über das Vorkommen, die Zusammensetzung und die Bildung von Eisenanhäufungen, Z. anorg. Chem. 22 (1899). 
Geologie bis jetzt die Auffassung noch nicht durchgedrungen ist, dals man die amorphen (kolloidalen) Substanzen unterscheiden mufs von den kristallinischen, was ihre Zusammensetzung und Konstitution anbetrifft. Formeln, die nur für kristallinische Verbindungen und auch für Mischkristalle ${ }^{1}$ gelten und nur gelten können, werden noch immer angewandt auf ähnliche Substanzen, die im amorphen Zuständen verkehren und Komplexe unbestimmter Zusammensetzung darstellen.

\section{§ III. Folgerungen aus $\S \mathrm{II}, \mathrm{A}, \mathrm{B}, \mathrm{C}$.}

Es hat sich ergeben, dals im V.S. allerlei Verhältnisse zwischen $\mathrm{SiO}_{2}$ und $\mathrm{Al}_{2} \mathrm{O}_{3}$ vorkommen, mit verschiedenen Resten von alkalinischen Basen.

Zur Abkürzung nenne ich die Verhältniszahlen zwischen:

$$
\begin{array}{llll}
5 & \text { und } 3^{5} & \ldots & \text { A } \\
3^{5} & \text { und } 2^{5} & \ldots & \text { B } \\
2^{5} & \text { und } 1 & \ldots & \text { C } \\
1 & \text { und } 0 & \ldots & \text { D }
\end{array}
$$

bei dem in Salzsäure löslichen Teil des V.S. A und B fand ich in den alluvialen Böden, aus Verwitterungsmaterial gebildet, welches von fern angeführt ist, $\mathrm{A}$ in sandigen Tonen, $\mathrm{B}$ in schwereren Tonen. $\mathrm{C}$ und $\mathrm{D}$ fand ich in vulkanischen und aus jungeruptiven Gesteinen gebildeten Böden, im allgemeinen in Böden die dureh Verwitterung von basischen Silikaten (Plagioklasen, Glimmer, Hornblende u. s. w.) entstanden sind. Ich fand Gemische in sehr verschiedenen Mengen, von B und C im Ton aus Surinam und im braunfarbigen Padas; von $\mathrm{C}$ und $\mathrm{D}$ im gelben und roten Padas und im Deliboden; sehr viel $\mathrm{D}$ in Lateriten.

Im allgemeinen ist $D$ leichterlöslich als $B$ und $A$.

Auch der in Schwefelsäure lösliche Teil des V.S. ergibt verschiedene Verhältnisse von $\mathrm{Al}_{2} \mathrm{O}_{3}$ zu $\mathrm{SiO}_{2}$, jedoch nicht so viele. Die gewöhnlichen alluvialen Tone ergaben sämtlich die Zahl 2.2-2, wie auch der braune Padas (dessen Ss.V.S in $b$ und $c$ 3-3.8 hat) und der (plastische) Deliboden XIII. Bei den vulkanischen und den nicht plastischen Lateritböden ist dieser Teil oft gering oder fehlt.

${ }^{1}$ Wie die Silikate sind, worin $\mathrm{Al}_{2} \mathrm{O}_{3}$ durch $\mathrm{Fe}_{2} \mathrm{O}_{3}$ und andere Sesquioxyde teilweise isomorphiseh vertreten sind $-\mathrm{K}_{2} \mathrm{O}$ durch $\mathrm{Na}_{2} \mathrm{O} ; \mathrm{CaO}$ dnrch $\mathrm{MgO}$, $\mathrm{FeO}, \mathrm{MnO} ; \mathrm{SiO}_{2}$ durch $\mathrm{SnO}_{2}$ u. s. w.

Z. anorg. Chem. Bd. 42. 
Doch ist der Teil bedeutend im plastischen Laterit XIV, jedoch er hat dasselbe Verhältnis wie das in 0 gelöste, nämlich 1.6.

Der Unterschied zwischen beiden Teilen des V.S. ist noch unerklärt. Warum der erste mit dem Verhältnis $\mathbf{\pm 5 - 3}$, oder 3-0 in Salzsäure löslich, und der zweite mit dem Verhältnis 2.2-2 (ja selbst 1.6) erst in Schwefelsäure löslich ist, scheint befremdend. Jedoch wie Zusammensetzung und Löslichkeit miteinander zusammenhängen, ist unbekannt. Es wäre möglich, dals das Ss.V.S. in einem weiteren oder anderen Stadium der Verwitterung verkehrte als das Sch.V.S., oder aus anderen Silikaten entstanden sei, oder dals metamorphosierende Wirkungen stattgefunden hätten. Es kommt mir vor, dafs das Problem noch ganz im Dunkelen liegt.

Viele Verhältniszahlen von A-D scheinen einer gewissen Stufe der Verwitterung eines Silikats zu entsprechen.

Viele Fragen tun sich vor. Besteht das V.S. aus nur einer Stufe der Verwitterung, oder aus zwei oder mehr, die von verschiedenen Orten herstammen und zusammengeschwemmt sind? In welchem Stadium der Verwitterung eines Silikats verkehrt es? Ist es ein Gemisch ron verschiedenen Stufen, deren Zusammensetzung darauf hinweist, dals das verwitternde Silikat kontinuierlich $\mathrm{SiO}_{2}$ und Basis verliert, und die Produkte von nachfolgenden Stadien der Verwitterung, auf primärer Lagerstätte, noch zusammen sind? Ist es ein Gemisch der Verwitterung von zwei oder von mehr Silikaten?

In allen diesen Fällen kann das V.S. keine chemische Verbindung mit einer chemischen Formel darstellen.

Das Material, das mir zur Verfügung steht, ist noch zu klein, um diese Fragen befriedigend $z u$ beantworten. Allerdings lälst sich schon schliefsen:

1. dafs in verschiedenen Böden hauptsächlich nur eine Stufe im Ss.V.S. und eine Stufe im Sch.V.S. gefunden ist, namentlich in den gewöhnlichen alluvialen Tonböden.

2. dafs bei den vulkanischen- und den Lateritböden mehrere Stufen erkennbar sind, und dals diese ans verschiedenen Silikaten herstammen können.

3. dafs die fortschreitende Verwitterung, bis zum Endprodukt Hydrargillit, sich am besten bei den Lateriten gezeigt hat. ${ }^{1}$

1 Die Analyse kann nur dann eine oder mehr bestimmte Stufen der Verwitterung anweisen, wenn in allen oder in einem Teil der Auszüge $a, b_{1}, b_{2}, c_{1}, c_{2}$ dieselbe V-Zahl gefunden wird.

So ergibt die Analyse II ( $Y$-Ton) in $a$ und $e$ dieselbe ZahI 3.1. In den 


\section{\& IV. Die alkalinischen Basen im V.S.}

Wenn die Chlorüre, Sulfate, Karbonate aus der Erde durch Wasser und sehr verdünnte Säure (z. B. Essigsäure) entfernt sind, dann löst Salzsäure, und danach Schwefelsäure noch $\mathrm{CaO}, \mathrm{MgO}$, $\mathrm{K}_{2} \mathrm{O}, \mathrm{Na}_{2} \mathrm{O}$ auf (auch $\mathrm{MnO}$ und $\mathrm{FeO}$, wenn diese zugegen sind) aus dem V.S. und den Humuskomplexen herstammend. Die Frage ist, ob sie in chemischer oder unbestimmter Verbindung (absorptiv) in der Erde sich befinden. Die Tabelle XXI enthält die Mengen derselben im salzsauren und im schwefelsauren Auszug, die Tabelle XXII und XXIII die Mengen in den darauffolgenden salzsauren Auszügen in Molek. berechnet auf $1 \mathrm{Mol} . \mathrm{Al}_{2} \mathrm{O}_{3}$. Die Tabelle XXIV enthält die prozentischen Mengen im Auszug mit verdünnter Essigsäure.

Nachdem durch Wasser die Chlorüre und Sulfate entfernt sind, löst verdünnte Säure aufser den Karbonaten diejenige Menge Basen, welche am schwächsten in den kolloidalen Silikat- und Humuskomplexen gebunden sind. (Siehe die Tabelle XXIV und die Auszüge a.) Von denselben darf man wohl behaupten, dal's sie absorptiv

Ton von Suriname VI ergeben $b, c_{1}, c_{2}$ dieselbe Zabl 2.7; für VII ergeben $b$ und $c$ die Zahl 3. Es kommen jedoch noch eine oder mehrere Stufen vor mit weniger $\mathrm{SiO}_{2}$ in $a$, doch ist es noch nicht auszumachen, welche Stufe in a mit der Stufe von 3 gemischt ist, denn die Analysen ergeben 1.3 als $1.2 \% \mathrm{Al}_{2} \mathrm{O}_{3}$ gelöst war, und 1.8 als $2.6 \mathrm{Al}_{2} \mathrm{O}_{3}$ gelöst war.

Die Padasarten zeigen eine Stufe von $B$ :

$$
\begin{aligned}
& \text { VIII . . 3.0-3.3 in } a, b_{1}, b_{2} \\
& \text { IX . . } 2.5 \text { in } a, b, c \\
& \mathrm{X} \cdot 2.3^{3} \text { in } b_{1}, b_{2}, c \text {. }
\end{aligned}
$$

und daneben einen löslicheren Teil der aus zwei oder mehr Stufen von D bestehen kann. Denn Pudas $(X)$ ergibt 0.77 in $k_{1}$ und $k_{2}$, indem $a$ ergibt 1.8. Also kann in $a$ ein Gemisch von 0.77 und 2.3 gelöst sein, oder noch eine Stufe zwischen diesen. In Padas IX enthält $k_{1}$ die Stufe 0.3 und $k_{2}$ die Stufe 0.9, oder ein Gemisch der Stufen 0.3 und 2.5, also zwei oder drei Stufen.

Der Deliboden XII weist auf wenigstens zwei Stufen, 0.9 und 2.2.

Die Laterite weisen auf mehrere Stufen und im Lateritton XIV tritt, neben der Stufe 0 eine Stufe (oder ein Gemisch von Stufen) 1.2, und sehr viel einer bestimmten Stufe 1.6 auf. Der Laterit XV hat wahrscheinlich hauptsächiich nur eine Stufe 1.4-1.5; Laterit XVI hauptsächlich zwei Stufen 0.3 bis 04 in $k_{1}$ und $k_{2}$ 1.5-1.7 in $b$, $c$ und Sch.

Im Laterit XVIII begegnen wir neben viel Hydrargillit, einem Gemisch von mehreren Stufen (0.9-1.8), jedoch in kleiner Menge.

Ebenso kommt im Granit-Laterit XX neben dem Hydrargillit noch eine kleine Menge vor, die entweder eine Stufe ist, oder ein Gemisch von mehreren Stufen zwischen 0 und \pm 1 . 
gebunden sind, und am meisten die Erscheinungen des Absorptionsvermögens der Erde durch Substitution hervorbringen. ${ }^{1}$ Die gröfste Menge des Kalks und auch der anderen Basen ist in diesem ersten Auszug enthalten, namentlich wenn die alluviale Böden noch frisch sind. Durch die stärkere Säuren in den Auszügen $b$ und $e$ werden diejenigen Mengen Basen gelöst, die im V.S. stärker gebunden sind, welcher Art dieser Band dann auch sein möge.

Die Frage tut sich nun hervor, inwiefern diese Basen aus dem in Salzsäure löslichen V.S., aus den Humussubstanzen oder aus dem U.V.S. ${ }^{2}$ herstammen.

Was die Humussubstanzen anbetrifft, die Padas- und Lateritböden enthalten davon sehr wenig, der Ton aus Surinam nicht viel. Was das U.V.S. anbetrifft, die Menge Base, auf 1 Mol. der gelösten Alaunerde berechnet, ist zu grofs, um auf dessen Rechnung gestellt zu werden (namentlich, wenn viel $\mathrm{Al}_{2} \mathrm{O}_{3}$ durch Salzsäure gelöst ist) wie die folgende Tabelle anzeigt.

\begin{tabular}{|c|c|c|c|c|c|}
\hline \multirow{2}{*}{$\begin{array}{c}\text { Folge- } \\
\text { nummer } \\
\text { d. Böden }\end{array}$} & \multirow{2}{*}{$\begin{array}{c}\text { Mol. } \mathrm{Al}_{2} \mathrm{O}_{3} \\
\text { gelöst }\end{array}$} & \multicolumn{3}{|c|}{ Auf 1 Mol. $\mathrm{Al}_{2} \mathrm{O}_{3}$} & \\
\hline & & Mol. $\mathrm{CaO}$ & Mol. MgO & $\mathrm{Mol} . \mathrm{K}_{2} \mathrm{O}$ & \\
\hline II & 2.53 & 0.24 & 0.85 & $0.16^{5}$ & Nach Abzug der in \\
\hline IV & 6.2 & 0.06 & 0.50 & 0.16 & Essigsäure lösliche \\
\hline $\mathrm{V}$ & 6.7 & 0.2 & 0.2 & 0.1 & Basen \\
\hline VII & 13.6 & 0.06 & 0.14 & 0.09 & \\
\hline
\end{tabular}

Aulserdem ist dafür ein Beweis, dafs der Gehalt an Kalk und an Kali oft in den darauffolgenden Auszügen $b, c, c_{1}, c_{2}$ wenig variiert, was der Fall nicht sein könnte, wenn die Basen gröfstenteils aus dem U.V.S. stammten, weil die Stärke der Salzsäure (in $b$ und $a$ verschieden) dann ibren Einflufs fühlen liefse. ${ }^{3}$ Man vergleiche dafür mit einander den Kalkgehalt in $b_{1}, b_{2}, e$ bei den drei Padasarten, und bei dem Surinam-Ton VI (Tab. XXIII und XXII). Der Kaligehalt nahm bei VI nur etwas zu.

${ }^{2}$ Wenn z. B. aus Lösungen von Kalisalzen $\mathrm{K}_{2} \mathrm{O}$ absorbiert, und äquivalente Mengen $\mathrm{CaO}, \mathrm{Na}_{2} \mathrm{O}, \mathrm{MgO}$ in Lösung kommen. Siehe meine 6. Verhandlung; Die Absorption aus Lösungen Z. anorg. Chem. 23 (1900), 358.

2 Es wäre ja möglich, dals ein kleiner Teil des U.V.S. namentlich die basischeren kristallinischer Silikate durch die Einwirkung der starken Salzsäure und darnach der Schwefelsäure angegriffen würden.

s Das $\mathrm{SiO}_{z}$-Verhältnis ist $\pm \mathbf{2 . 7}$ in $b, c, c_{1}$. 
Wo die Verwitterung weiter fortgeschritten ist, wie für den in a löslichen Teil des V.S. von Padas IX and $\mathrm{X}$, in den vulkanischen Böden von Malang und Deli und in den Lateriten, da ist der Gehalt an alkalinischen Basen nur gering.

Im V.S. sind nur die Magnesia und namentlich das Kali von Bedeutung.

Das Ergebnis ist also: 1. dafs die alkalinischen Basen wohl ein Bestandteil des V.S. sind, jedoch nicht in genügender Menge und zu sehr variierend, um eine chemische Verbindung anzunehmen mit einer chemischen Formel $\left(\mathrm{SiO}_{2}\right)^{m} \cdot\left(\mathrm{Al}_{2} \mathrm{O}_{3}\right)^{n} \cdot(\mathrm{MO})^{o} \cdot\left(\mathrm{H}_{2} \mathrm{O}\right)^{p}{ }^{1}{ }^{1}$ worin $m$, $n, o, p$, ganze und einfache Zahlen sind. 2. Je nachdem die Verwitterung weiter fortgeschritten ist, nimmt die Menge Basen ab.

\section{§ V. Das Wasser im V.S.}

Poröse und kolloidale Stoffe absorbieren Wasserdampf in kontinuierlicher Abhängigkeit von Dampfspannung des Mediums und von Temperatur. Dazu gehört also das Wasser, welches durch das V.S. und den Humus aufgenommen oder abgegeben wird, wenn die Dampfspannung des Mediums zunimmt oder abnimmt, und wenn die Temperatur abnimmt oder zunimmt. ${ }^{2}$ Das Wasser, welches bei der Erhöhung der Temperatur allmählich ausgetrieben wird, ist im allgemeinen Absorptionswasser, selbst bei höherer Temperatur. Es ist doch bekannt, dals kolloidale Stoffe noch bei einem Druck von tausenden Atmosphären etwas Wasser festhalten können, und ebenso bei sehr hohen Temperaturen. Jedoch in gewissen Fällen kann auch chemisch gebundenes Wasser bei Erhöhung der Temperatur ausgetrieben werden, z. B. wenn Hydrargillit oder Göthit anwesend ist. Hydrargillit, wie oben gesagt, verliert erst Wasser über $180^{\circ}$, Göthit bei $300^{\circ}$. Es ist darum wichtig, die Mengen Wasser zu bestimmen, welehe die Erde bei verschiedenen Dampfdrucken und verschiedenen Temperaturen verliert, ${ }^{2}$ im Zusammenhang mit der Zusammensetzung und der Menge des V.S., sowohl des in Salzsäure als des in Schwefelsäure löslichen Teils.

Bis jetzt sind noch keine Untersuchungen in dieser Richtung $\mathrm{K}_{2} \mathrm{O}, \mathrm{Na}_{2} \mathrm{O}$.

${ }^{1}$ In dieser Formel bedeutet $\mathrm{MO}$ eine alkalinische Basis $\mathrm{CaO}, \mathrm{MgO}$,

2 Siehe über die Absorption von Wasserdampf, bei der gewöhnlichen Temperatur, und bei verschiedenen Dampfdrucken, dureh den plastisehen Ton die folgende Abhandlung S. 314. 
ausgeführt. Mein Material ist noch zu beschränkt, um daraus allgemeine Schlusse zu folgern. In Tab. XXIV sind einige Bestimmungen zusammengestellt von Wasser, welches die lufttrockne Erde auf $1 \mathrm{Mol} . \mathrm{Al}_{2} \mathrm{O}_{3}$ des V.S. verliert.

$$
\begin{aligned}
& \alpha . \ldots \text { über konz. Schwefelsäure bei } \pm 15^{\circ} \\
& \beta \ldots \text { bei } 15^{\circ}-100^{\circ} \\
& \gamma \ldots \text { bei } 100^{\circ} \text { bis Glühhitze }
\end{aligned}
$$

$\alpha$ ist das schwächer gebundene, $\beta$ und $\gamma$ das stärker gebundene Wasser, mit dem Verstande, dafs das Wasser stärker gebunden ist, je nachdem es bei höherer Temperatur ausgetrieben wird.

Daraus ergibt sich schon:

1. Dals die gewöhnlichen Tone viel schwach gebundenes Wasser ( $\alpha$ ) enthalten, und rom stärker gebundnen Wasser $\pm 2 \mathrm{Mol} . \mathrm{H}_{2} \mathrm{O}$. Man bedenke dabei, dafs diese Zahlen berechnet sind auf die ganze Menge. $\mathrm{Al}_{3} \mathrm{O}_{3}$ im Ss.V.S. und in Sch.V.S. zusammen.

2. Dafs bei den Böden eruptiven Ursprungs auch solche vorkommen, die auf jeden Mol. $\mathrm{Al}_{2} \mathrm{O}_{3}$ des V.S. weniger von $\alpha$ Wasser und $\beta-\gamma$ Wasser enthalten.

3. Dafs die Laterite sehr wenig schwach gebundenes Wasser ( $\alpha$ und $\beta$ ) enthalten, und wahrscheinlich nur dann über $2 \mathrm{Mol} . \mathrm{H}_{2} \mathrm{O}$ stark gebundenes Wasser besitzen, wenn sie kristallinischen Hydrargillit $\left(\mathrm{Al}_{2} \mathrm{O}_{3} \cdot 3 \mathrm{H}_{2} \mathrm{O}\right)$ enthalten.

\section{§ VI. Der löslichste Teil des V.S.}

Der Teil des V.S., welcher in verdünnten Säuren sich löst, ist wohl der wichtigste kolloidale Teil des Bodens, ein Komplex von Kieselsäure, Alaunerde, Eisenoxyd, Humus, worin auch die Phosphorsäure und ein bedeutender Teil der alkalischen Basen absorptiv gebunden sind. Es bekleidet die Bodenteilchen, besonders die feinsten, wie für das Eisenoxyd und die Phosphorsäure vor kurzem durch

${ }^{1}$ Für die Berechnung von $\gamma$ ist für das Eisenoxyd 1 Mol. $\mathrm{H}_{2} \mathrm{O}$ in Rechnung gebracht, und vom Wasserverlust bei $100^{\circ}$ (oder $15^{\circ}$ ) bis Glühbitze abgezogen. Um zu beurteilen, welchen Einflufs die Unsicherheit dieser Annahme in den Zahlen von $\gamma$ hervorbringen könnte, sind die Zablen in der 5. Spalte ohne diesen Abzug berechnet. Es erhellt daraus, dafs diese Unsicherheit für das stärker gebundene Wasser nur bei den eisenreichen Erden XVII u. XVIII von einiger Bedeutung sein könnte. Für das schwach gebundene Wasser ist die Unsicherheit grofs bei den hellgelben Padas (IX), wie unten behandelt ist (S. 297). 
ScHLÖsING ${ }^{1}$ bewiesen ist. Es enthält verhältnismälsig am meisten alkalinische Basen wie Tab. XXIV und Tab. XXII (Auszug a) anzeigen, Das sogenannte Absorptionsvermögen des Bodens kommt denselben in erster Stelle zu, also das Vermögen um Wasser, Basen, Phosphorsäure zu absorbieren und Basen (besonders Kali) aus Salzlösungen unter Auswechslung zu absorbieren. ${ }^{2}$ In diesem Bodenteil finden die meisten physikalischen und chemischen Bewegungen statt, wozu die Erscheinungen des chemischen Metamorphismus gehören, welche der Boden durch die zirkulierende Bodenlösung, durch den Regen, durch den atmospherischen Staub und durch die Düngerstoffe erfährt. Ich unterlasse jedoch hier die nähere Behandlung desselben, weil ich mich jetzt zu der Zusammensetzung des V.S. im allgemeinen (Verhältnis von $\mathrm{SiO}_{2} \quad \mathrm{zu}^{\mathrm{Al}_{2} \mathrm{O}_{3}}$ ) zu beschränken wünsche.

\section{§ VII. Die Löslichkeit des V.S. in Salzsäure.}

Die Analysen zeigen allen, dafs das V.S. um so leichter in Salzsäure und auch in verdünnter Lauge gelöst wird, je nachdem es basischer ist und einer weiter fortgeschrittenen Verwitterung entspricht, und dabei ärmer an alkalinischen Basen ist. Also findet man den Teil, dessen $\mathrm{SiO}_{2}$ - Verhältnis \pm 1 und darunter ist, ganz oder gröfstenteils in $a$ oder in $k$. Nur wenn viel Hydrargillit anwesend war, enthielt auch $c$ davon. Wenn das basischere V.S. entfernt war, und wenn das rückständige durch Salzsäure zersetzbare Ss.V.S. eine grölsere $\mathrm{SiO}_{2} \cdot \nabla$ erhältniszahl hat, dann wird dieses nur durch längere Digestion, allmählig zersetzt und in Lösung gebracht; die Zersetzung wird beschleunigt durch ein Übermars von Salzsäure, noch mehr durch Temperaturerhöhung, am meisten durch die gröIsere Stärke der Säure. Das gilt auch dann, wenn die in $b_{1}, b_{2}, c_{1}, c_{2}, c_{3}$ gelösten Teile des V.S. dieselbe Zusammensetzung besitzen, wie es bei II, IV, VI und VII, und bei dem Padas der Fall war. Wenn also die Zersetzung in diesem Fall nur allmählig stattfindet und eine längere Zeit erheischt, so hat man wahrscheinlich nicht zu tun

1 Compt. rend. 135 (1903), 601.

Siehe darüber meine Abhandlungen: Das Absorptionsvermögen des Bodens. L. V. Stat. 35 (1888), 104-136. Die Zusammmensetzung der Ackererde, das kolloidale Silikat. L. V. Stat. 37 (1890), 347-373. Die Absorption von Stoffen aus Lösungen. Z. anorg. Chem. 23 (1900), 358. 
mit einem Gemisch von V.-Silikaten verschiedener absoluter Löslichkeit, sondern vielmehr mit der Schwerlöslichkeit des V.S., d. h. mit dessen Lösungsgeschwindigkeit, die klein ist. Um zu prüfen, inwiefern die grölsere Feinheit der Erdteilchen die Lösungsgeschwindigkeit beeinflufst, wurde der folgende Versuch angestellt, ${ }^{1}$ wobei die Erde durch eine einfache Schlämmung (Aufrühren und Abgiefsen) in neun Portionen verteilt wurde, und die Auszüge $a, b, c_{1}$ und $e_{2}$ von den drei letzten Portionen bereitet und analysiert.

Diese enthielten an gelöster Alaunerde und in Salzsäure unlösliche Substanz:

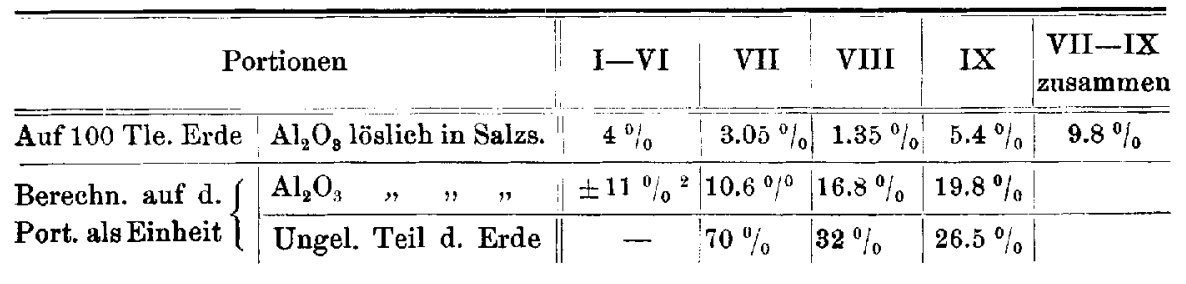

$15 \mathrm{~g}$ Erde von $\mathrm{V}$ (Suriname) wurde mit Wasser behandelt (nicht gerieben), bis sie sich ganz darin verteilt hatten; dann mit etwas verdünnter Salzsäure und Lauge kalt digeriert, um zementierendes Eisenoxyd und Humussubstanz zu lösen; darauf mit grofsen Mengen Wasser aufgerührt in flachen Schalen, nicht höher als $1 \mathrm{dm}$. Was sich nach einer Ruhe von $1 / 4,1 / 2,1,5$ Minuten, $1 / 2,1$ Stunde, 1, 2 Tage abgesetzt hatte, wurde nach Trocknung an der Luft gewogen. Was nach 2-3 Tagen noch sehwebend war, wurde mit einer Säure koaguliert und gesammelt. So wurde erhalten:

\begin{tabular}{|c|c|c|c|c|c|c|c|c|c|}
\hline Portion & I & II & III & IV & V & VI & VII & VIII & IX \\
\hline $\begin{array}{c}\text { Zeit } \\
\% \text { der Erde }\end{array}$ & $\begin{array}{l}1 / 4 \\
4\end{array}$ & $\begin{array}{l}1 / 2 \\
1.9\end{array}$ & $\begin{array}{c}1^{\prime} \\
2.5\end{array}$ & $\begin{array}{c}5^{\prime} \\
8.2\end{array}$ & $\begin{array}{c}1 / 2 \mathrm{St} . \\
8.8\end{array}$ & $\begin{array}{l}1 \mathrm{St} . \\
9.6\end{array}$ & $\begin{array}{c}1 \mathrm{~T} . \\
29\end{array}$ & $2 \mathrm{~T}$ & $\begin{array}{c}\text { schweb. } \\
28^{2}\end{array}$ \\
\hline
\end{tabular}

Die Portionen VII und IX wurden ausgezogen

a $1 / 2$ Stunde mit $25 \mathrm{ccm}$ Salzsäure von $1.03^{4}$ spez. Gew. bei $55^{\circ}$.

$b 1 / 2 \quad, \quad 25, \quad " \quad, 1.1 \quad$ " $, \quad, 100^{\circ}$

$e_{1} 1$ " 40 " $\quad$ " $\quad 1.2 \quad$ " $"$ bei Siedehitze.

$e_{2}$ Wiederholung von $e$.

Ebeuso die Portion VIII. Doch waren die Mengen Säure der Menge von VIII proportionell also $1 / 4$ von den obigen.

a Berechnet: durch Substraktion der in VIII, IX and X erhaltenen Alaunerde von dem bekannten Gehalt der Erde an Alaunerde und Umrechnung anf $35 \%$ Erde, dem Gewichte von I-VI. Diese Zahl ist also nicht sehr genau. 
Die Mengen $\mathrm{Al}_{2} \mathrm{O}_{3}$ in den verschiedenen Auszügen, auf die Portion als Einheit berechnet, betrugen:

\begin{tabular}{c|c|c|c}
\hline & VII & VIII & IX \\
\hline$a$ & 0.85 & 1.1 & 1.3 \\
$b$ & 3.4 & 4.0 & 4.5 \\
$c_{1}$ & 3.2 & 8.5 & $10.6^{5}$ \\
$c_{9}$ & 3.2 & $\frac{3.2}{16.8}$ & $\frac{3.4}{19.8^{5}}$
\end{tabular}

Es ergibt sich also 1. dals die feinsten Teile (VII-IX) $2 / 3$ der Erde betragen, 2. dafs auch in diesen Portionen VII-IX der Gehalt an ungelöster Substanz abnimmt von $70-26.5 \%$ auf die Portion als Einheit. Da nun auch von der feinsten Portion (IX), die $19.8^{6} \mathrm{Al}_{2} \mathrm{O}_{3}$ in $a-c_{2}$ (auf die Portion als Einheit berechnet) enthält, am meisten in $c$, gelöst wird $(10.6 \%)$, so folgt daraus, dafs das Ss.V.S. mit dem $\mathrm{SiO}_{2}$-Verhältnis \pm 2.7 sich am besten in konzentrierter Salzsäure löst, bei Erwärmung, auch was die feinsten Teile anbetrifft.

Sind die feinsten Teile in $c_{1}$ gelöst, dann scheint das restierende der drei letzten Portionen (VII-IX) gleiche Mengen des noch rückständigen Ss.V.S. $z u$ enthalten $\left(3.2-3.4 \% \quad \mathrm{Al}_{2} \mathrm{O}_{3}\right)$, welche durch eine längere Einwirkung von kochender starker Salzsäure gelöst werden.

Im Auszug $a$ ist derjenige Teil des Ss.V.S. gelöst, der eine $\mathrm{SiO}_{2}-$ Verh.-Zahl < 2.5 hat, und also leichtlöslicher ist; er ist wieder bei der feinsten Portion IX am reichlichsten vertreten. $\mathrm{Ob}$ in den Auszügen $b-c_{2}$ Teile gelöst sind die eine verschiedene Löslichkeit besitzen, unabhängig von der grölseren oder kleineren Feinheit derselben, lälst sich nicht ausmachen. ${ }^{1}$

Es hat sich wieder bei dieser Untersuchung ergeben, dafs man durch ein gröfseres Volumen der Säure, durch Erwärmung, durch eine stärkere Säure in derselben Zeit, und durch Wiederholung der Extraktion mit derselben Säure, mehr in Lösung bekommt, ${ }^{2}$ auch wenn das V.S. dieselbe Zusammensetzung hat. Darum ist es un-

${ }^{1} \mathrm{Es}$ wäre möglich, dals trotz des gleichen Gehaltes an $\mathrm{SiO}_{2}$, kleine Differenzen im Gehalt an alkalinischen Basen Verschiedenheit in dem Grade der Verwitterung, und dadurch in der Löslichkeit veranlalsten. Doch sind die Differenzen im Gehalt an $\mathrm{K}_{2} \mathrm{O}$ und selbst $\mathrm{MgO}$ zu klein, um daraus etwas abzuleiten.

${ }^{2}$ Dr. SJollema und Dr. Kobus haben dieselbe Erfahrung gemacht. KoBts hat zwei vulkanische Erden auf Jaya (Res. Pasoeroean, Zuckerunternehmungen 
bedingt nötig, dals man bei Vergleichung von verschiedenen Böden mit einander, gleiche Mengen Erde mit gleichen Volumina Säure, von gleicher Stärke, während gleicher Zeiten, ausziehen muls, und die Stärke der Säure bei allen auf dieselbe Weise variieren.

\section{VIII. Das Eisenoxyd im Boden.}

Das Eisenoxyd kommt auf verschiedene Weise im Boden vor, im mehr oder weniger freien Zustande: 1. im freiesten Zustande in Adern und kleineren oder grölseren Konkretionen angehäuft, und ist dann am leichtesten löslich. 2. Es sind Sand- und Tonteilchen damit bekleidet, und man kann annehmen, dafs es sich beschwerlicher in Salzsäure löst (also stärkere Salzsäure unter Erwärmung oder längere Einwirkung der Säure bedarf) je nachdem die Schicht fester anhaftet. Im allgemeinen kann man stellen, dafs das $\mathrm{Fe}_{2} \mathrm{O}_{3}$ des Bodens grölstenteils in den Auszügen $a$ und $b$ gelöst wird, das übrige bis auf einen kleinen Teil in $c$, so dals die Erde die Farbe, welche rom Eisenoxyd herrührt, nach $a$ und $b$ meist verloren hat. 3. Es kann ein Bestandteil des Verwitterungssilikats ausmachen und dann zugleicher Zeit mit der Alaunerde desselben in Lösung kommen. 4. Es ist fraglich, ob es kristallinisch vorkommen kann. 1. Im Auszug $a$ bekommt man das $\mathrm{Fe}_{3} \mathrm{O}_{3}$ der Adern und Konkretionen und daneben das auf und zwischen den Bodenteilchen abgesetzte, wenn es nur lose anhaftet. Das beweisen die folgenden Beispiele:

VI (Surinam) hat eine gleichmälsig graue Farbe und zeigt keine hervortretende Farbe von Eisenoxyd; VII (Sur.) ist ganz dieselbe Bodenart, doch hat eine rotgelbliche Farbe:

\begin{tabular}{c|c|c|c}
\hline \hline & VI & VII & Differenz \\
\hline \hline Ganzer Gehalt an $\mathrm{Fe}_{2} \mathrm{O}_{3}$ & $4.1 \%$ & $5.1 \%$ & $1 \%$ \\
Davon in $a$ gelöst & $0.9 \%$ & $1.8 \%$ & $0.9 \%$
\end{tabular}

Ketegan und Maron) anffolgend extrahiert; mit ihrem $2{ }_{1}^{1}$ fachen Gewicht Salzsäure von $2 \%, 4 \%, 8 \%$, während 2 Stunden bei Siedehitze, und während 24 Stunden mit kalter konzentrierter Salzsäure, indem jede Extraktion fünfmal wiederholt wurde. Die 20 Extrakte wurden analysiert $\left(\mathrm{Al}_{2} \mathrm{O}_{3}, \mathrm{Fe}_{2} \mathrm{O}_{8}, \mathrm{MnO}, \mathrm{CaO}, \mathrm{MgO}\right.$, $\mathrm{K}_{2} \mathrm{O}, \mathrm{P}_{2} \mathrm{O}_{5}$; die Bestimmungen von $\mathrm{SiO}_{2}$ sind natürlich ohne Wert). Daraus ergab es sich, dafs auch eine fünfmalige Wiederholung der Extraktion mit Säure derselben Stärke nicht genügte, um die Erde für diese Säure zu erschöpfen. J. D. Kobus und Th. Marr: Bijdragen tot het Onderzoek van Tropisehe Gronden. Archief voor de Java Suikerindustrie 1902. Mededeelingen van het Proefstation Oost-Java. 
Die rotgelbliche Farbe von VII ist nach $a$ verschwunden, und die Differenz des Eisenoxydgehalts zwischen VI und VII $(1 \%)$, findet man im Auszug $a$ ungefähr zurück, wie obige Tab. anweist.

So lehrt auch die Untersuchung, dals in einem der drei Padasarten (IX) das Eisenoxyd nur lose zwischen den Bodenteilchen anhaftet, dagegen viel fester in VIII und $X$.

\begin{tabular}{l|c|c|c} 
Padas & Gelbe IX & Braune VIII & Rote X \\
\hline Ganzer Gehalt an Fe, $\mathrm{O}_{3} \%_{0}$ & 6.9 & 8.7 & 13.8 \\
Davon in $a$ (nach 10 Minuten) & 5.7 & 2.3 & 2 \\
Davon in $b$ & 0.9 & 4.6 & 8.3 \\
Davon in $e$ & 0.05 & 0.8 & $1.3^{5}$
\end{tabular}

Der Padas ist ein Boden, dessen Teilchen durch Eisenoxyd und gewils auch durch $\mathrm{SiO}_{2}$-armes V.S. zusammen geklebt (zementiert, agglutiniert) sind, wie die Kisenockerböden (Raseneisenstein $=$ Eisenockerböden in den Niederlanden), in der Diluvialsandformation.. ${ }^{1}$ Der gelbe Padas IX ist nicht sehr hart und lälst sich sehr leicht feinreiben. Der braune und der rote sind dagegen sehr hart. Wie man sieht, ist von IX schon $85 \%$ des $\mathrm{Fe}_{2} \mathrm{O}_{3}$ in a gelöst, von den beiden anderen nur 26 und $15 \%$.

2. Dafs das Eisenoxyd in Böden, die davon weniger als $5 \%$ enthalten und keine rötliche Farbe zeigten, ziemlich fest anbängt und die Tonteilchen bekleidet, beweist die Analyse von (Surinam) $\mathrm{VI}$ u. VII. In den folgenden Tabellen ist die Menge $\mathrm{Al}_{2} \mathrm{O}_{3}$ (2. Spalte) berücksichtigt, die neben dem $\mathrm{Fe}_{2} \mathrm{O}_{3}$ (3. Spalte) in den Auszügen $a-c_{2}$ in Lösung kam, und ist das Eisenoxyd in Mol. berechnet auf $1 \mathrm{Mol} . \mathrm{Al}_{2} \mathrm{O}_{3}$ (4. Spalte):

\begin{tabular}{|c|c|c|c|c|c|c|}
\hline \multirow[b]{2}{*}{ Auszug } & \multicolumn{3}{|c|}{ VI Surinam } & \multicolumn{3}{|c|}{ VII Surinam } \\
\hline & $\begin{array}{c}\% \mathrm{Al}_{2} \mathrm{O}_{3} \\
\text { gelöst }\end{array}$ & $\begin{array}{c}\% \mathrm{Fe}_{2} \mathrm{O}_{3} \\
\text { gelöst }\end{array}$ & $\begin{array}{c}\text { Mol. } \mathrm{Fe}_{2} \mathrm{O}_{3} \\
\underset{\text { anf }}{1} \text { Mol. } \mathrm{Al}_{2} \mathrm{O}_{8}\end{array}$ & $\begin{array}{c}\% \mathrm{Al}_{2} \mathrm{O}_{3} \\
\text { gelöst }\end{array}$ & $\begin{array}{c}\% \mathrm{Fe}_{2} \mathrm{O}_{3} \\
\text { gelöst }\end{array}$ & $\begin{array}{c}\text { Mol. } \mathrm{Fe}_{2} \mathrm{O}_{8} \\
\quad \operatorname{auf} \\
1 \mathrm{Mol} . \mathrm{Al}_{2} \mathrm{O}_{8}\end{array}$ \\
\hline$a$ & 1.4 & 0.9 & 0.4 & 1 & $1.7^{8}$ & $1.0^{8}$ \\
\hline$b$ & 3.0 & $1.9^{8}$ & 0.4 & 2 & $1.5^{4}$ & $0.4^{7}$ \\
\hline$c_{1}$ & 7.0 & $1.1^{2}$ & 0.1 & 5 & $1.5^{5}$ & $0.1^{8}$ \\
\hline$c_{z}$ & 2.2 & $0.1^{7}$ & $0.0^{5}$ & 3 & 0.2 & $0.0^{3}$ \\
\hline Summe & $13.6 \%$ & $4.15 \%$ & & 11 & $\overline{5.0^{7}}$ & \\
\hline
\end{tabular}

1 Siehe meine Abhandlung: Eisenanhäufungen in und unter Mooren, Z. anorg. Chem. 22 (1899), 313, 345, 366, 374. 


\begin{tabular}{|c|c|c|c|c|c|c|}
\hline \multirow[b]{2}{*}{ Auazug } & \multicolumn{3}{|c|}{ IV $\mathrm{Y}$-Boden } & \multicolumn{3}{|c|}{ XIII Deliboden } \\
\hline & $\begin{array}{l}\% \mathrm{Al}_{2} \mathrm{O}_{3} \\
\text { gelöst }\end{array}$ & $\begin{array}{l}\% \mathrm{Fe}_{2} \mathrm{O}_{2} \\
\text { gelöst }\end{array}$ & $\begin{array}{c}\text { Mol. } \mathrm{Fe}_{2} \mathrm{O}_{3} \\
\text { auf } \\
1 \text { Mol. } \mathrm{Al}_{2} \mathrm{O}^{3}\end{array}$ & $\begin{array}{l}\%_{0} \mathrm{Al}_{2} \mathrm{O}_{3} \\
\text { gelöst }\end{array}$ & $\begin{array}{c}\% \mathrm{Fe}_{2} \mathrm{~F}_{3} \\
\text { gelöst }\end{array}$ & $\begin{array}{l}\text { Mol. } \mathrm{Fe}_{2} \mathrm{O}_{3} \\
\text { auf } \\
1 \text { Mol. } \mathrm{Al}_{2} \mathrm{O}_{3}\end{array}$ \\
\hline$a$ & 1.9 & 2.1 & 0.7 & 2.9 & 2.3 & 0.5 \\
\hline$e_{1}$ & 4.5 & 2.9 & 0.4 & 7.9 & 2.3 & 0.18 \\
\hline Summe & $6.4 \%$ & $5.0 \%$ & & $10.8 \%$ & $4.6 \%$ & \\
\hline
\end{tabular}

Die 2. Spalte gibt an, wie weit die Zersetzung und Lösung des Ss.V.S. durch die Salzsäure fortgeschritten ist. Im Auszug $e$ von VI, wenn nur $4.4 \% \quad \mathrm{Al}_{2} \mathrm{O}_{3}$ gelöst sind, ist das Verhältnis 0.4. Das Verbältnis nimmt ab bis 0.1, indem noch $7 \% \mathrm{Al}_{2} \mathrm{O}_{3}$ sich lösen $\left(c_{1}\right)$, und in $e_{2}$ beträgt es nur $0.0^{5}$. Ähnlich in VII, ${ }^{1}$ und in den Tonböden IV und XIII. Auch bei den Padasböden nimmt das Verhältnis des gelösten $\mathrm{Fe}_{2} \mathrm{O}_{3}$ zu der gelösten $\mathrm{Al}_{2} \mathrm{O}_{3}$ ab: von $b_{1} \mathrm{zu}$ $b_{2}$, und von $b_{2}$ zu $c$.

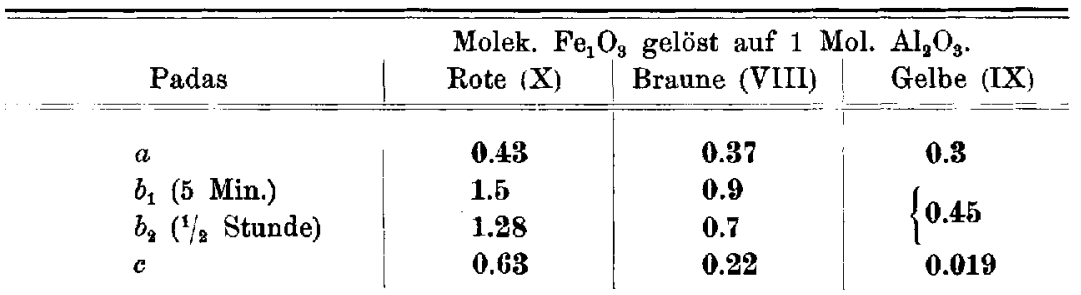

Dafs das Verhältnis für $a$ nicht das höchste, sondern niedriger ist als in $b_{1}$ und $b_{2}$ und selbst bei $\mathbf{X}$ niedriger als in $c$, liegt daran, dafs der Padas viel leicht lösliches $\mathrm{SiO}_{2}$-armes $\nabla . S$. enthält, welches schon in $a$ gelöst wird. Ist das entfernt, dann folgt für das übrige

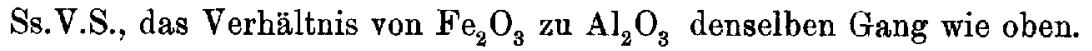

Wenn nun das Eisenoxyd die Tonteilchen bekleidet, so müssen die feinsten Teilchen auch das meiste Eisenoxyd enthalten, denn sie besitzen verhältnismälsig die grölste OberHäche. Ich hatte dann auch schon seit langem beobachtet, dals in schweren Tonböden das abgeschlämmte verhältnismäfsig das reichste an Eisenoxyd ist. Für den Tonboden von Surinam, der so viel Ss.V.S. enthält, habe ich es ausführlich untersucht, indem ich die Schlämmproben VII, VIII und IX analysierte.

Es ergaben sich:

${ }^{1}$ Siehe über den Auszug $a$ oben auf S. 291. Zeile $1-3$ ซ. o. 


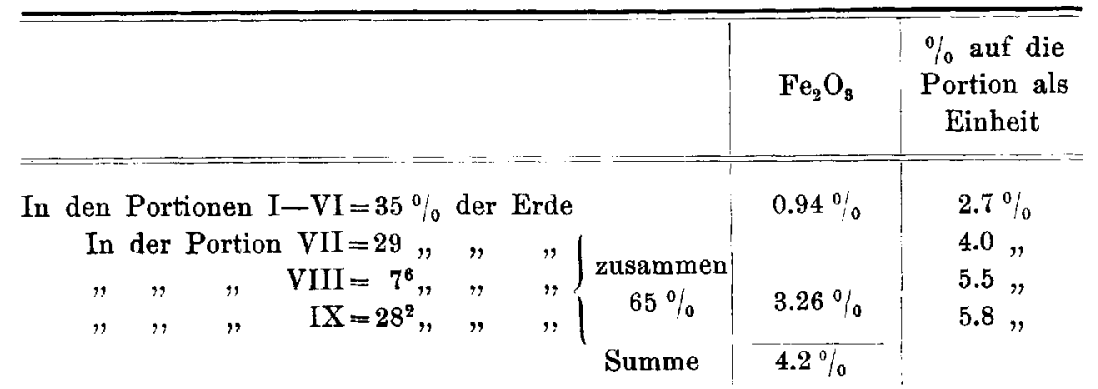

Die Analyse der Auszüge $a-e$ ergab auf die Portion als Einheit:

\begin{tabular}{|c|c|c|c|}
\hline Portion & VII & VIII & IX \\
\hline$a$ & $0.4^{5}$ & & 1.2 \\
\hline$b$ & 2.3 & $\{3.5$ & 2.4 \\
\hline$c_{1}$ & 0.7 & 1.7 & 1.8 \\
\hline \multirow[t]{2}{*}{$c_{8}$} & 0.6 & 0.3 & $0.3^{5}$ \\
\hline & $4.0 \%$ & $\overline{5.5 \%}$ & $5.8 \%$ \\
\hline
\end{tabular}

Die vorletzte Tabelle ergibt:

Das feinste (Portion IX) enthält reichlich zweimal mehr $\mathrm{Fe}_{2} \mathrm{O}_{3}$ als die schnell sich senkenden Portionen I-VI (35\% der Erde), worin die $22 \%$ Quarz und unlösliches Silikat, obschon auch diese sehr klein sind. Die letzte Tabelle ergibt:

Die feinste Portion enthält auch verhältnismärsig das meiste leichtlösliche $\mathrm{Fe}_{2} \mathrm{O}_{3}$ (Auszug a).

Die Analyse der Portionen VII-IX bestätigt die obige Berechnung (S. 291) von dem Verhältnis des Eisenoxyds zur Alaunerde, bei der auffolgend in Lösung kommenden Mengen des Ss.V.S. ${ }^{1}$

3. Es fragt sich nun, ob etwas Eisenoxyd ein Bestandteil des gelösten V.S. ist, und also für die Säure zugänglich wird, je nach-

${ }^{1}$ Das Molekül-Verhältnis nimmt ab von 0.4 und 0.6 bis 0.1 und 0.07 .

Mol. $\mathrm{Fe}_{2} \mathrm{O}_{3}$ auf 1 Mol. $\mathrm{Al}_{2} \mathrm{O}_{8}$.

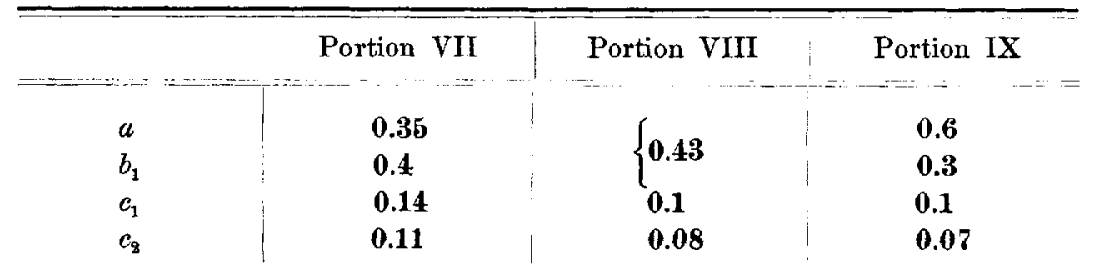

Nach der Tabelle auf S. 291 nimmt das Verhältnis ab von 0.4 bis 0.05 . Die Übereinstimmung ist genügend. 
dem die Alaunerde gelöst wird. Die in $c_{2}$ gelösten Mengen können dazu gehören, und in diesem Falle auch ein kleiner Teil des $\mathrm{Fe}_{2} \mathrm{O}_{3}$ in $b_{1}$ und $b_{9}$. Jedoch die Mengen in $c_{1}$ sind gering:

\begin{tabular}{|c|c|c|c|}
\hline & VI (Surinam) VII (Surinam) & im Mittel & \\
\hline Mol. $\mathrm{Fe}_{2} \mathrm{O}_{3}$ & $0.0 \mathrm{~s}$ & 0.04 & auf $1 \mathrm{Mol} . \mathrm{Al}_{2} \mathrm{O}_{3}$ \\
\hline
\end{tabular}

und von derselben Ordnung als der Gehalt an $\mathrm{Fe}_{2} \mathrm{O}_{3}$ im kaolinischen Verwitterungssilikat, wie die folgende Tabelle ergibt:

Molek. $\mathrm{Fe}_{2} \mathrm{O}_{3}$ auf 1 Mol. $\mathrm{Al}_{2} \mathrm{O}_{3}$ im Sch.V.S.

\begin{tabular}{c|c|c|c|c|c|c}
\hline \hline Auszug & VII Surinam & $\begin{array}{c}\text { II Wieringer- } \\
\text { meer }\end{array}$ & IV Y & $\begin{array}{c}\text { V Java } \\
\text { (Kening })\end{array}$ & XII Deli & im Mittel \\
\hline Sch. & 0.03 & 0.06 & 0.03 & 0.03 & 0.06 & 0.04
\end{tabular}

und dabei kann immer noch eine Spur aus dem U.V.S. herstammen. Leider besitzen wir noch kein Mittel, um in einer Erde das anbaftende, durch eine starke Adhäsion gebundene Eisenoxyd von einem chemisch gebundenen oder wenigstens das Verwitterungssilikat durchdringenden Eisenoxyd zu unterscheiden. ${ }^{1}$

4. Kann es kristallinisch vorkommen, mit drei oder ein Mol. Wasser, oder als kristallinisches Eisensilikat. Das ist noch nicht gehörig untersucht. ${ }^{2}$ Ich erinnere daran, dafs KLOBBrE in

1 H. Kramers (Mitteilungen aus der Versuchsstation Oost-Java, Nr. 34) hat 1893 vorgeschlagen, dafür eine Lösung von Ammoniumcitrat zu benutzen, und auf einen Padas (Pegandan am Fulse des Tengger Gebirges, Residenz Probolingo) angewandt. Weil nun wenig oder kein $\mathrm{Fe}_{2} \mathrm{O}_{3}$ in Lösung kam, dagegen ein frischer Hydrogel von Eisenoxyd, auch wenn es bei $100^{\circ}$ getrocknet war, sich wohl in Ammoniumcitratlösung löste, so sehlofs er daraus, dafs das $\mathrm{Fe}_{2} \mathrm{O}_{8}$ im Padas nicht frei vorkam, sondern mit einer Säure zu einem in Wasser unlöslichem Salze verbunden war. Das Mittel ist ganz ungenügend. Es ist gar nicht bewiesen und auch nicht annehmbar, dafs das $\mathrm{Fe}_{2} \mathrm{O}_{3}$ in beiden Fällen denselben physikalischen Zustand und also auch dieselbe Löslichkeit in Ammoniumeitrat besitzt. Die Säure, woran es nach Kramers gebunden wäre, mürste Kieselsăure sein.

${ }^{2}$ Bei seiner mikroskopischen Untersuchung glaubte Herr vaN GELDER im braunen Padas VIII und auch im roten Padas X (aber weniger) kristallinisches Eisenoxyd zu erkennen, indem der gelbe Padas (IX) nur amorphes Eisenoxyd zeigte. Nun gaben der rote und braune Padas noch ziemlich viel Eisenoxyd im Auszug $e$. 
einem Raseneisenstein mikroskopische Kristalle von Ferrisilikat, so viel mir bekannt, zuerst entdeckt hat. ${ }^{1}$ Sie bildeten starke polarisierende Stäbchen, lang 18, breit 3 Mikrons, mit abgerundeten Enden, hatten eine schwach gelbe Farbe, enthielten $\mathrm{Fe}_{2} \mathrm{O}_{3}$ und schieden mit Salzsäure einen Hydrogel von $\mathrm{SiO}_{2}$ ab.

BaUER beschreibt das Eisenoxyd des Dioritlaterits teilweise als amorph (homogen und isotrop), teilweise als eine Anhäufung zu konzentrisch schaligen radialfaserigen Aggregaten, welche eine schwache Doppelbildung zeigen. Es ist die Frage, ob man das schon als kristallinisches Eisenoxyd oder Eisenoxydhydrat betrachten darf. ${ }^{2}$ BAUER fragt sich nun, ob $\mathrm{Fe}_{2} \mathrm{O}_{3}$ in den Lateriten etwa mit Hydrargillit isomorph gemischt vorkommen kann; obwohl er das wohl erwarten könnte, findet er es doch nach der mikroskopischen Untersuchung sehr zweifelhaft. Das feinschuppige Aggregat ist ja ganz farblos. Ich bemerke, dals eine isomorphe Mischung allein für den kristallinischen Zustand gelten kann. Man mufs ein isomorphes Gemisch in einem kristallinischen Gebilde (Mischkristall) von einem Gemisch amorpher Stoffe unterscheiden. In den Mischkristallen sind die Bestandteile als verschiedene Bausteine im kristallinischen Gebäude zu betrachten. In den amorphen oder komplexen Mischungen sind die Bestandteile in willkürlichen Verhältnissen agglutiniert und bilden Absorptionsverbindungen.

Wir kennen bis jetzt nur kristallinischen Hydrargillit $\left(\mathrm{Al}_{2} \mathrm{O}_{8}\right.$. $3 \mathrm{H}_{2} \mathrm{O}$ ) frei von $\mathrm{Fe}_{3} \mathrm{O}_{3}$, durch das Mikroskop beobachtbar. Das Eisenoxyd ist oft daneben und in den Adern und Höhlen dazwischen

$\begin{array}{rcc} & \text { Rote Padas } & \text { Braune Padas } \\ & \mathrm{Fe}_{2} \mathrm{O}_{3} & \mathrm{Fe}_{2} \mathrm{O}_{3} \\ \mathrm{Fe}_{2} \mathrm{O}_{3} & 0.8^{9} \% & 1.35 \% \\ \text { Auf } 1 \mathrm{Mol} . \mathrm{Al}_{2} \mathrm{O}_{3} & 0.63 \mathrm{Mol} & 0.22 \mathrm{Mol} .\end{array}$

Es bleibt also möglich, dafs ein Eisensilikat mit dem Aluminiumsilikat verwachsen ist, doch kann nur eine nähere Untersuchung dies ausweisen.

x Sie wurden gefunden in den knollenartigen Konkretionen von diluvialen Sandkörnern mit mikrokristallinischen Eisenspat. Diese Knollen lagen in einer Sandschicht von $1.25 \mathrm{~m}$ unter einer Schicht von $1.5 \mathrm{~m}$ Hochmoor in der Nähe vom Dorfe Sellingen (Provinz Groningen, Niederlande) an der deutsch-niederländisehen Grenze. (Mitgeteilt von G. ReInders und mir in der Sitzung der Kön. Akad. der Wiss. Amsterdam am 29. Dez. 1900. Der Raseneisenstein unter Hochmoor zu Sellingen und im Hochmoor zu Valthermond.)

- Eine Anzahl đünner übereinander liegender Schalen, wie beim Glaskopf, welche zwischen gekreuzten Nicols ein Sphärolithkreuz zeigen, das auf eine fein radialfaserige Struktur hinweist. BAUER. S. 126 und 128. 
angehäuft. Ich halte es vorläufig für ganz unwabrscheinlich, dafs Mischkristalle von $\mathrm{Al}_{2} \mathrm{O}_{3} \cdot 3 \mathrm{H}_{2} \mathrm{O}$ und $\mathrm{Fe}_{2} \mathrm{O}_{3} \cdot 3 \mathrm{H}_{2} \mathrm{O}$ vorkommen. Dagegen kann es amorphe wasserhaltige Komplexe geben von $\mathrm{Fe}_{2} \mathrm{O}_{3}$ mit $\mathrm{SiO}_{2}$-armer Alaunerde.

\section{\& IX. Der Wassergehalt des Eisenoxyds.} Boden?

Wie viel Wasser gehört dem freien Eisenoxyd im lufttrocknen

Der Hydrogel des $\mathrm{Fe}_{2} \mathrm{O}_{3}$ aus einer verdünnten Lösung eines $\mathrm{Fe}_{2} \mathrm{O}_{3}$-Salzes durch Ammon abgeschieden, hält eine grofse Menge Wasser absorbiert und entspricht keiner chemischen Formel. Der Gel, selbst wenn er ausgeprefst ist, enthält noch $\pm 20 \mathrm{Mol} . \mathrm{H}_{2} \mathrm{O}$ $(80 \%)$ und nachdem er noch zwischen Filtrierpapier ausgeprefst ist, $7^{5}-5 \mathrm{Mol} . \mathrm{H}_{2} \mathrm{O}$. Er scheint dann lufttrocken und verliert noch, während er 5 Jahre an der Luft verblieben, Wasser bis auf $\pm 3.5 \mathrm{Mol}$. Was oben rom Hydrogel der Alaunerde gesagt ist (S. 275) gilt auch von dem Hydrogel des Eisenoxyds. Durch Aussetzen an niedrigen Wasserdampfdrucken verliert er Wasser und stellt sich mit diesem Druck in Gleichgewicht, wie ich ausführlich bestimmt habe. Indessen modifiziert er sich. Auch wenn er mit dem Gehalt von \pm 5 Mol. $\mathrm{H}_{2} \mathrm{O}$ an der Luft, oder unter Wasser mehrere Jahre verbleibt, modifiziert er sich allmählich und verliert an Absorptionsvermögen, ${ }^{1}$ so dafs er an der Luft oder im mit Wasserdampf gesättigten Raum nur ein Teil des verlorenen Wassers wieder aufnimmt. ${ }^{2}$

Wenn also der Hydrogel von $\mathrm{Fe}_{2} \mathrm{O}_{3}$, aus einer Lösung eines Eisensalzes bereitet, mit der Zeit soviel Wasser verliert, lälst sich nicht erwarten, dals das amorphe Eisenoxyd im Boden, das durch Verwitterung entstanden ist, oder aus einer FeO-Lösung durch Oxy-

1 Die isotherme des kolloidalen $\mathrm{Fe}_{2} \mathrm{O}_{3}$ bei $15^{\circ}$. 2. anorg. Chem. 30, (1899), 185. Der Hydrogel und das kristallinische $\mathrm{Hydrat}$ von $\mathrm{Fe}_{2} \mathrm{O}_{3}$. Journ. prakt. Chem. 46 (1892), 497. L'hydrogel de $\mathrm{Fe}_{2} \mathrm{O}_{3}$ im Recueil. Trav. chim. Pays-Bas. 7 (1888), 106.

2 Z. B.:

Frisch bereitet

Nach 6 Jahren

Nach 16 Jabren

7 Jahre unter Wasser an der Luft:

$\pm 4.5$

3.4

1.7

4.4 (eben trocken
geworden) im trocknen Raum:

1.6

1.05

$0.7^{3}$

1.1

bei $100^{\circ}$ 
dation gebildet und ahgesetzt ist, einen hohen Wassergehalt (über \pm 1 Yol.) besitzt, wenigstens nicht bei $100^{\circ}$ gebunden hält.

Die folgende Tabelle zeigt, wieviel Mol. Wasser die eisenreiche Lateritböden über Schwefelsäure und bei $100^{\circ}$ rerlieren, auf $1 \mathrm{Mol}$. $\mathrm{Fe}_{2} \mathrm{O}_{3}$ berechnet:

\begin{tabular}{|c|c|c|c|c|c|c|c|c|c|}
\hline & \multicolumn{3}{|c|}{$\begin{array}{l}\text { Laterit XVII } \\
\text { sehr eisenreich }\end{array}$} & \multicolumn{3}{|c|}{ Laterit XVIII } & \multicolumn{3}{|c|}{ Dioriet-Laterit XIX } \\
\hline & $\mathrm{Fe}_{2} \mathrm{O}_{3}$ & $\begin{array}{l}\text { Wass } \\
\text { in troc } \\
\text { Raum }\end{array}$ & $\begin{array}{l}\text { lust } \\
130^{\circ}\end{array}$ & $\mathrm{Fe}_{3} \mathrm{O}_{3}$ & $\begin{array}{l}\text { Wass } \\
\text { in tro } \\
\text { Raum }\end{array}$ & eriust $110^{\circ}$ & $\mathrm{Fe}_{2} \mathrm{O}_{3}$ & $\begin{array}{l}\text { Wass } \\
\text { in tro } \\
\text { Raur }\end{array}$ & $\begin{array}{l}\text { verlust } \\
\text { bei } 110^{\circ}\end{array}$ \\
\hline & 42.9 & 1.20 & 0.6 & 35.7 & 1.6 & 3.1 & 27 & $0.6^{3}$ & $1.4^{3}$ \\
\hline Molek. & 26.6 & 7 & 3.3 & 22.3 & 9 & 17 & 15.5 & 3 & 8 \\
\hline Verhïltn. & 1 & $0.2^{\mathrm{a}}$ & $0.1^{3}$ & 1 & 0.4 & $0.7^{6}$ & 1 & 0.2 & $0.5^{2}$ \\
\hline
\end{tabular}

Das Verhältnis $\mathrm{Fe}_{2} \mathrm{O}_{3}$ zu $\mathrm{H}_{2} \mathrm{O}$ beträgt bei dem eisenreichsten Laterit nur $0.2^{6}+0.1^{3}=0.5$, und bei XVIII 1.2. Da nun der grölste Teil dieses Wassers, das als Absorptionswasser zu betrachten ist, vom amorphen Teil des V.S. stammen mufs (namentlich in XVIII) so folgt daraus, dafs das Eisenoxyd im Laterit noch kein halbes Mol. schwach gebundenes $\mathrm{H}_{2} \mathrm{O}$ enthalten kann. Da nun amorphes Eisenoxyd, wie es aus dem Hydrogel entsteht, im frischen Zustande bei $100^{\circ} 1.4 \mathrm{H}_{2} \mathrm{O}$ and nach Modifizierung durch die Zeit weniger als $1.0 \mathrm{H}_{2} \mathrm{O}$ enthält, so kann man annehmen, dafs im allgemeinen dem Eisenoxyd (im Lateritboden und auch in vielen anderen Böden) ein Wassergehalt zukommt von wenig mehr als 1 Mol. und bei $100^{\circ}$ eher unter als über ein Molekül. Diese Annahme wird durch die Betrachtung auf S. 277 bestätigt, weil bei dieser Annahme für den kristallinischen Hydrargillit in Diorit- und Granit-Laterit drei Mol. $\mathrm{H}_{2} \mathrm{O}$ berechnet werden können. Wenn ich auch zugebe, dals es Böden gibt, worin das freie amorphe $\mathrm{Fe}_{2} \mathrm{O}_{3}$ mehr als $1 \mathrm{Mol}^{\mathrm{H}} \mathrm{H}_{2} \mathrm{O}$ enthält, ${ }^{1}$ namentlich wenn das schwach gebundene Wasser mitgezählt wird, so erlauben die früheren Wasserbestimmungen noch keine Berechnungen in dieser Hinsicht. Ich bemerke nur, dals der Brauneisenstein $11 / 2 \mathrm{H}_{2} \mathrm{O}$ enthält, und dafs das Eisenoxyd des hellgelben Padas sehr wahrscheinlich mehr Wasser gebunden hält als der rote und der braune Padas. ${ }^{1}$

${ }^{1}$ Das Eisenoxyd des hellgeiben Padas $\left(6.7 \% \mathrm{Fe}_{9} \mathrm{O}_{3}\right)$ enthält wahrscheinlich mehr als 1 Mol. Wasser, welche Menge schwach gebunden ist, und welche er tcilweise über Schwefelsäure bei $15^{\circ}$, teilweise bei Erhitzung bis $100^{\circ}$ verZ. anorg. Chem. Bd. 42 . 
Wird das Eisenoxyd unter gewissen, uns noch unbekannten Umständen kristallinisch, wie wir dies bei der Alaunerde jetzt beobachtet haben, dann kann es 1 oder 2 oder $3 \mathrm{Mol} . \mathrm{H}_{2} \mathrm{O}$ chemisch binden. ${ }^{1}$ Göthit hat die chemische Formel $\mathrm{Fe}_{2} \mathrm{O}_{3} \cdot \mathrm{H}_{2} \mathrm{O}$, und ist, wie ich früher gefunden, bestündig bis $300^{\circ}$.

\section{$\S$ X. Die Plastizität.}

Was ist die Ursache der Plastizität?

BAUER und Dubors sagen, dals der Laterit nicht plastisch ist. DuвoIs erwähnt jedoch, dals Zwischenstufen bekannt sind, welche man Ton oder Lehm nennen kann. Der Laterit XIV ist plastisch.

Der gewöhnliche alluviale Ton, nicht allein in dem gemärsigten Klima, sondern auch in den Tropen ist plastisch, und um so plastischer, je nachdem der Gehalt an V.S. gröfser ist. Die Verhältnifszahl ist $\mathbf{5 - 2 . 7} \mathrm{SiO}_{2}$.

Der Padas, der neben $\mathrm{SiO}_{2}$-armen V.S. eine bedeutende Menge Ss.V.S. mit dem Verhältnis $3-2.5 \mathrm{SiO}_{2}$ besitzt, ist jedoch nicht plastisch. Die Laterite und die Delierde XIII, sowohl die viel Hydrargillit (XVIII-XX) als die viel $\mathrm{SiO}_{2}$-armes V.S. enthalten $(\mathrm{XV}-\mathrm{XVII})$ sind nicht plastisch. ${ }^{2}$ Die Delierde XIII dagegen ist etwas plastisch, und enthält einen kaolinartigen 'Teil im V.S. Der Laterit XIV isi sehr plastisch, obgleich er im V.S. viel $\mathrm{SiO}_{2}$-armes Silikat enthält und daneben viel V.S. mit dem Verhältnis $1.6 \mathrm{SiO}_{2}$, wovon ein grofser Teil durch Schwefelsäure gelöst wird.

liert. Der rote $\left(14 \% \mathrm{Fe}_{2} \mathrm{O}_{3}\right)$ und der braune $\left(8.7 \% \mathrm{Fe}_{2} \mathrm{O}_{3}\right)$ enthaiten mehr $\mathrm{Fe}_{2} \mathrm{O}_{3}$ als der gelbe Padas, und verlieren doch viel weniger Wasser über Schwefelsäure und bei $100^{\circ}$. Das würde stimmen mit der Ansicht von Baues, der meint, dafs der Wassergehalt des $\mathrm{Fe}_{2} \mathrm{O}_{\mathbf{3}}$ in den Böden sehr verschicden sein kann, und sie demzufolge verschiedeue gelbe und rote Farben besitzen. Leider fehlt es woch ganz an brauchbaren Wasserbestimmungen, um diese Ansicht zu bestätigen. Die Farbe wird auch beeinflul'st durch die Menge des Eisenoxyds und die Mischung derselben mit dem Ton; sie mul's eine andere sein, wem das Eisenoxyd stellenweise angehäuft ist, als wenn es die feinen Bodenpartikelchen gleichmälsig in dieser dïnnen Schicht bekleidet.

${ }^{1}$ Inwiefern Turgit, Pyrrhosiderit, Xanthosiderit, Limnit, denen die chewischen Formeln, $1 \mathrm{Mol}$. $\mathrm{Fe}_{2} \mathrm{O}_{3}$ mit resp. 1/2, 1, 2, $3 \mathrm{Mol} . \mathrm{H}_{2} \mathrm{O}$ gegeben sind, wahre kristallinische ehemische Verbindungen sind, muls noeh näher untersucht worden.

${ }^{2}$ Auch Schtösing hat beobachtet, dars die freic oder $\mathrm{SiO}_{2}$-arme Alaunerde nicht plisstiseh ist. 
Es ist also noch keine Beziehung zwischen der Plastizität und der Zusammensetzung des V.S. herzustellen; nur ist es sicher, dafs der Hydrargilit und das V.S. mit dem Verhältnis $<1 \mathrm{SiO}_{2}$ nicht plastisch ist. Die Ursache der Plastizität ist wohl noch unbekannt.

\section{$\S \mathrm{XI}$. Konstitution des Verwitterungsilikats.}

Wie muls man das V.S. betrachten? Doch wohl nicht als ein Gemisch von chemischen Verbindungen $\left(\mathrm{SiO}_{2}\right)^{m(}\left(\mathrm{Al}_{2} \mathrm{O}_{3}\right)^{n}(\mathbf{M O})^{\circ}\left(\mathrm{H}_{2} \mathrm{O}\right)^{p}$ (worin $m, n, o, p$ ganze einfache, jedoch variable Zahlen sind), welche nachfolgend aus dem kristallinischen Silikat entstehen, indem $m$ und $o$ fortwährend abnehmen und $\mathrm{H}_{2} \mathrm{O}$ aufgenommen wird. ${ }^{1}$ Denn diese Vorstellung, dals es ein Gemisch wäre von wahren chemischen Verbindungen, ist in dieser Form ohne weiter nicht annehmbar. Das V.S. mülste dann durch Lösungsmittel in die verschiedenen Verbindungen aufzulösen sein, welche eine konstante Zusammensetzung haben würden.

L's stellt sich dagegen vor als ein Komplex von $\mathrm{SiO}_{2}, \mathrm{Al}_{2} \mathrm{O}_{3}$ und kleine Mengen alkalinischer Basen in unbestimmten Verhältnissen. Solche Komplexe kommen viel vor, doch können wir ihre Natur und Zusammensetzung nicht näher erklären. Wir können vorläufig durch diese Vorstellung nur zum Ausdruck bringen, mit welchen anderen Erscheinungen und Zuständen, wobei auch Verbindungen oder Komplexe in unbestimmten Äquivalentverhältnissen auftreten, der Verwitterungsprozefs Analogie hat.

Ich weise zuerst auf die Zersetzung eines chemischen Hydrats bei höheren 'Iemperaturen, wie ich diese bei kristallinischem Alu. miniumhydroxyd und kristallinischem Berylliumhydroxyd beobachtet habe. Als wahre chemische Hydrate ist ihre Zusammensetzung innerhalb gewisser Grenzen von Temperatur- und Wasserdampfspannung konstant. Das erste fängt erst bei $170^{\circ}$, das zweite bei $210^{\circ}$ an Wasser zu verlieren und amorph zu werden. Diese Zersetzung schreitet bei höheren Temperaturen allmählich fort, ohne dafs sich ein bestimmtes niedrigeres Hydrat bei einer gewissen Temperatur bildet. ${ }^{2}$ Die Zersetzung geht also nicht mit Sprüngen, wie bei den wahren

1 MO bedeutet $\mathrm{CaO}, \mathrm{MgO}, \mathrm{K}_{2} \mathrm{O}, \mathrm{Na}_{2} \mathrm{O}$. FeO.

2 3. Abhandlung. Z. anorg. Ohem. 18 (1898). Umsetzung der Kristalle, Hydrate in amorphe Substanzen, S. 126-128. 
Hydraten, ${ }^{1}$ ist aber eine kontinuierliche. Die Zusammensetzung ändert sich also auch kontinuierlich. Die Eigenschaften der amorph gewordenen Verbindung sind denen der Hydrogels von $\mathrm{Al}_{2} \mathrm{O}_{3}$ und $\mathrm{BeO}$ ähnlich geworden, da die Wiederaufnahme von Wasser, wie der Verlust in kontinuierlicher Abhängigkeit von Temperatur, Wasserdampfdruck, und von Modifikationen der amorphen Substanz stattfindet. ${ }^{2}$

Ich weise zweitens auf die Zersetzungsprodukte von kristallinischen Salzen durch Wasser, wenn daraus noch zunehmender Verlust von Säure oder Base keine kristallinische, sondern amorphe Substanzen entstehen, die ein unbestimmtes Komplex zu bilden scheinen. So bei Wismut-, Antimonsalzen u. s. w. Sie können unter Umständen wieder in den kristallinischen Zustand übergehen. mit einer bestimmten Zusammensetzung.

Drittens ist es fraglich, inwiefern die unbestimmten Verwitterungsprodukte einige Übereinstimmung oder Analogie haben mit den $\mathrm{Ab}$ sorptionsverbindungen (oder mit den festen Lösungen), deren Natur und Eigenschafter ${ }^{3}$ ich schon oft beschrieben habe. Diese entstehen z. B. wenn zwei oder mehr Kolloiden im Solzustande und in unbestimmten Mengen gemischt werden und gelatinieren, wodurch keine chemischen Verbindungen nach bestimmten Verhältnissen, sondern Absorptionsverbindungen in unbestimmten Verhältnissen (Agglutinationen) erhalten werden - z. B. von $\mathrm{SiO}_{2}$ mit $\mathrm{Al}_{2} \mathrm{O}_{3}$ oder mit $\mathrm{Fe}_{2} \mathrm{O}_{3}$

1 d. h. so lange sie wahre Hydrate bleiben und also nicht amorph werden. Das ist für die höheren $\mathrm{Hydrate}$ von $\mathrm{Ba}(\mathrm{OH})^{2}$, von vielen Salzen u. s. w. genügend bewiesen.

2 Je nach der Modifikation, die sie erfahren haben durch Erhitzung, und andere Umstände absorbieren solche Stoffe in Wasserdampf, bei jeder Wasserdampfspannung, eine verschiedene Menge Wasser, ohne dals ein einfaches Äquivalentverhältnis auftritt. Siehe die Tabelle XVIII in meiner 3. Abhandlung über die Absorption, Seite 146. Man kann wohl nicht annehmen, dafs das Oxyd bei der Entwässerung durch Hitze sich fortwährend mehr polymerisiert, so dals immer mehrere Molek. Oxyd mit 1 Mol. $\mathrm{H}_{2} \mathrm{O}$ chemisch verbunden bleiben, und das erhitzte Hydrat, also ein Gemisch von hydratierten Polymeren wird, welches bei der Wiederaufnahme von Wasser höher hydratierte Polymeren bildet.

${ }^{3}$ Diese sind: Amorpher Zustand des absorbierenden Komponents. Kein. Verhältnis der Komponenten nach Äquivalenten.

Die Zusammensetzung abhängig vom Bau des amorphen Komponents und von den Modifikationen, die er erfahren hat.

Die Zusammensetzung nicht homogen, sondern kontinuierlich abhängig von der Temperatur und von der Konzentration der Lösung an der Substanz, welche absorbiert wird (im Falle eines Gases, vom Dampfdruck der Gasphase). 
oder mit beiden im Gel-Zustande. ${ }^{1}$ Diese Vereinigung des Gels hat eine ganz andere Natur, als eine wahre chemische Verbindung, $\left(\mathrm{SiO}_{2}\right)^{m} \cdot\left(\mathrm{Al}_{2} \mathrm{O}_{3}\right)^{n}$ oder $\left(\mathrm{SiO}_{2}\right)^{m}\left(\mathrm{Fe}_{2} \mathrm{O}_{3}\right)^{n}$ u. s. w., worin $m$ und $n$ einfache ganze Zahlen sind, und welche kristallinische Form annehmen kann Weiter entstehen Absorptionsverbindungen zwischen Kolloiden und sogenannte Elektrolyten, wenn Gels Säuren, Basen, Salze u. s. w. aus Lösungen absorbieren. Man kann auf diese Weise Komplexe bereiten, die verschiedene Komponenten im amorphen Zustande enthalten (z. B. $\mathrm{SiO}_{2}, \mathrm{Al}_{2} \mathrm{O}_{3}, \mathrm{Fe}_{2} \mathrm{O}_{3}, \mathrm{FeO}, \mathrm{MgO}, \mathrm{CuO}$ u. s. w.), welche aufserdem verschiedene Elektrolyte als Ionen oder als Salze absorbiert halten, und zwar in Mengen abhängig von der Konzentration der Lösung, woraus die Substanzen absorbiert sind. ${ }^{2}$

In der Natur kommen solche Komplexe unzweifelhaft vor. Ich weise besonders auf den weifsen und den roten Bolus. Ein näheres Studium der Verwitterungsprodukte in dieser Hinsicht scheint mir sehr erwünscht, um über die Konstitution derselben mehr Licht zu

Die Stärke der Verbindung kontinuierlich abnehmend oder zunehmend mit der Zunahme oder Abnahme eines Komponents.

Siehe meine früheren Abhandlungen, und die letzte, 6. Abbandlung: Die Absorption von Stoffen aus Lösungen, Z. anorg. Chem. 23 (1900), 321-372.

1 Ibidem, S. $333-334$.

${ }^{2}$ Neulich hat Brutz sehr wichtige Untersuchungen iber diese Absorptionsverbindungen publiziert: Über die gegenseitige Beeinflussung kolloidal gelöster Stoffe (Ber. deutsch. chem. Ges. 37 (1904), 1095). Das Verhalten einiger anorganischen Kolloide zur Faser, ibidem, S. 1766. Über die Einwirkung von $\mathrm{As}_{2} \mathrm{O}_{3}$ a uf frischem $\mathrm{Hydrogel}$ von $\mathrm{Fe}_{2} \mathrm{O}_{3}$, ibidem, S. 3138. Ein Versuch zur Deutung der Agglutinierungsvorgänge (Nachrichten der k. Ges. d. Wis.s. zu Götingen 1904, 1). Er schreibt: „Alle diese Gebilde, welche dureh Vereinigung von Gels oder Sols mit einander und mit Kristalloiden oder Elektrolyten zustande kommen, sind als Adsorptionsverbindungen zu betrachten. sofern es sich nicht unzweifelhaft um wahre chemische Verbindungen handelt. Die Ursache für ihre Entstehung ist in erster Linie in dem physikalischen Zustande der Kolloidstoffe zu suchen". Es freut mich, dals Herr Butz in seinen Arbeiten zu denselben Ansichten gekommen ist, als ich schon seit 1888 vertreten habe, da ich zuerst Absorptions- (oder Adsorptions)verbindungen angenommen, charakterisiert und beschrieben habe. Auch BHEDia, PaUli haben jetzt Adsorptionsverbindungen angenommen. Die Verbindungen von Farbstoffen mit Textilfasen betrachtet auch Zacharias als Absorptionsverbindungen (Zur Chemie der Textilfasern: Zeitschr. Farben- und Textil-Ckemie 2 (1908), Heft 12), und G. Gaceotri beschreibt und charakterisiert die sogenannten Metallverbindungen der Eiweifskörper auf Grund seiner Untersuchung nach der Phasenlehre als Absorptionsverbindungen, (Hoppe Seycer, Zeitschr. Physiol. Chem. 40 (1904), 492). 
verbreiten. Dals bei dor Verwitterung neben den amorphen Proúukten auch kristallinische chemische Verbindungen entstehen können, ist selbstverständlich. Der Hydrargillit ist davon ein Beweis, wie viele andere kristallinische chemische Verbindungen, z. B. Eisenspat (Siderit), Vivianit, Ferrisilikat u. s. w.

\section{§ XII. Der Verwitterungsprozeß.}

Aus dem obigen erhellt es genügend, dals allerlei Grade oder Stufen der Verwitterung vorkommen.

Der neue Befund, dafs diese in dem Laterit zu der Bildung von freier Alaunerde vorgehen kann, hat die Frage erhoben, ob die Zusammensetzung der ursprünglichen Silikate oder das Klima davon die Ursache sein kann, oder beide.

Es scheint annehmbar, dals eine Verwitterung, welche $\mathrm{SiO}_{2}$ armes V.S. hervorbringt, eigen ist an Gesteinen, wic Diorit und Diabas, welche Plagioklasen, Hornblende, Glimmer u. s. w. enthalten. Der Laterit entsteht auch wirklich daraus, und damit ist in Einklang, dals in den meisten Lateriten eine Anhäufung von Eisenoxyd stattfindet und dafs der Hydrargillit oft noch die Struktur der Hornblende zeigt. Jedoch die Beobachtung, dals der Granitlaterit der Seychelleninseln an primärer Lagerstätte aus Granit entstanden ist, soll nach BAder beweisen, dals auch normale Feldspate eine Verwitterung erfahren können, die in $\mathrm{SiO}_{2}$-armes, und selbst in $\mathrm{SiO}_{2}$ freies Alaunerdehydrat von kristallinischer Form endet.

Darum ist die Hypothese aufgeworfen, ob nicht 1. das Klima der Tropen für diese Verwitterung notwendig wäre, 2. ein Verwitterungsprodukt wie Bauxit, das auch in gemälsigten Zonen gefunden wird, in einer früheren Periode entstanden wäre, als auch dort ein tropisches Klima herrschte.

Jedoch in den Tropen kommt auch ein V.S. mit der Zahl $\pm \mathbf{3}$ vor, und es ist nicht bewiesen, dals dieses überall aus Granit entstanden ist. Und zweitens ist es gar nicht bewiesen, dals V.S. mit den Zahlen 2-0 nicht in gemälsigten Zonen gebildet wird. Im Gegenteil:

„In neuerer Zeit, sagt BAUER, hat man mehrfach Hydrargillit unter den Zersetzungsprodukten des Feldspats mancher Gesteine gefunden und zwar sind diese Vorkommnisse wahrscheinlich gar nicht so selten; sie wurden aber häufig verwechselt mit Kaolin." Über- 
dies kommen die beiden Verwitterungsprodukte nebeneinander vor, wie BAUER rom Bauxit am Vogelsberg erwähnt: die Bauxitbrocken liegen in einem Tone, die auch durch Verwitterung eines basaltischen Gesteins gebildet ist. Beide Prozesse sind also an derselben Stelle vorgegangen. Die obigen Untersuchungen haben gelehrt, dals nicht allein $\mathrm{Hydrargillit,}$ sondern $\mathrm{SiO}_{2}$-arme Alaunerde vielfach neben dem gewöhnlichen T'on vorkommt (BAUER).

Über den Gang des Verwitterungsprozesses, welcher Laterit hervorbringt, sind auch Hypothesen aufgeworfen. LieвRICH vermutet (und auch G. C. Dubois erwähnt es), dals Pyrit in den ursprünglichen Gesteinen rorkommt und den primären (eluvialen) Laterit hervorbringt. Durch die Oxydation des Pyrits entsteht Schwefelsäure, welche die Alaunerde auflöst und fortführt und anderwärts in Form von Konkretionen ablagert. Oder es wird dadurch (Dubors) aus dem Silikat ein $\mathrm{Al}_{2} \mathrm{O}_{3}$-reicheres Produkt gebildet. Dieses mufs dann durch die Einwirkung von Gewässern, die kohlensaures Alkali enthalten, in Alaunerde übergehen. Baukn führt dagegen an, das der Hydrargillit in dem Seychellenlaterit nicht in Konkretionen auftritt, sondern die ursprüngliche Struktur des Silikats, woraus er entstanden ist, bewahrt. Überdies ist keine der erwähnten Reaktionen beobachtet.

Dal's Geologen solche Vermutungen aufwerfen, welche eigentlich nur einigermalsen Pbantasien ${ }^{1}$ scheinen, beweist wohl, wie wenig von den Verwitterungsprozessen bekannt ist, nicht allein von der Lateritbildung, sondern auch ron der Tonbildung. Wir können uns davon am besten Rechenschaft geben, wenn wir bemerken, dals fast auf alle Fragen die Antwort ausbleiben mufs.

Bleibt der Verwitterungsprozefs der gewöhnlichen allurialen Tone stehen auf $\pm \mathbf{4}-\mathbf{3}$, oder $\pm \mathbf{3}-\mathbf{2 . 5}$ ? Oder können sie allmählich ineinander übergehen? Mit anderen Worten, dauert der Verwitterungsprozers, und dadurch eine Anreicherung an $\mathrm{Al}_{2} \mathrm{O}_{3}$, noch immer fort? Findet diese vielleicht so langsam statt, dal's wir es nicht bemerken? Sind diese Verhältnisse etwa in gewissem Sinne Ruhepunkte der Verwitterung normaler Feldspathen, weil der Ton den Verwitterungsagentien entzogen ist, woran er auf seiner ursprünglichen Bildungsstätte ausgesetzt war? Können die Diorite, Diabase, Anamesite ein V.S. geben, das viel schneller Kieselsäure verliert? Was ist der Unterschied zwischen dem kaolinischen und dem in Salzsäure lös-

${ }^{1}$ Denn es lassen sich mit gleichem Rechte audere Prozesse ersinnen, so lange keine Beobachtungen vorliegen. 
lichen Teil des V.S.? Kann das ersie in das zweite allmählich übergehen oder nicht? Geht es noch immer darin über, oder umgekehrt? Sind sie Verwitterungsprodukte desselben oder verschiedener Feldspate? Können metamorphische Wirkungen auf die Verwitterungsprodukte stattfinden und deren Zusammensetzung ändern? Sind die Tone und Laterite Gemische ron gewissen Verwitterungsstufen, oder stellen sie auf primärer Lagerstätte ein Gemisch kontinuierlicher Verwitterungsstufen dar?

Da es jetzt wahrscheinlich ist, dafs der Feldspat sowohI zu dem V.S. I und II, als zu III und IV verwittern kann, so müssen wir uns gestehen, dafs wir mit den Umständen und Agentien, wodurch die Verwitterung so verschiedene Stufen erreichen kann, in ihrem Zusammenhang gänzlich unbekannt sind und auch nicht wissen, wo die viele Kieselsäure bei der Lateritbildung bleibt. Nur steht es fest, dafs, wie Dubors sagt, ein Verwitterungsprozefs vorkommt, welcher die Tendenz hat, das Silikat allmählich in Hydrargillit umzusetzen, und ist es wahrscheinlich, dals dabei Absetzungen ron Quarz und Bildung von sekundären Silikaten auftreten können.

Die obigen Ergebnisse und Betrachtungen, welche nur als höchst bescheidene Beiträge zur Kenntnis der Verwitterungsböden und des Verwitterungsprozesses betrachtet werden dürfen, und welche zu so vielen unbeantworteten Fragen Anleitung gegeben haben, machen es nach meiner Ansicht sehr wünschenswert, dals zuerst viele genaue Analysen des Verwitterungssilikats gemacht werden, und zwar auf primärer Lagerstätte, in verschiedenen Bodenarten, in verschiedenen Himmelsgegenden, und in verschiedenen Stadien der Verwitterung. Diese müssen mit der Zusammensetzung des ursprünglichen Gesteins, woraus sie entstehen, verglichen werden. Eine Bestimmung der Kieselsäure und der alkalinischen Basen in den Verwitterungsprodukten darf dabei nicht ausbleiben. Vielleicht kann dabei die hier befolgte Methode von Nutzen sein.

\section{Nachschrift.}

Im September-Hefte dieser Zeitschrift bespricht PaUl RoHLAND die Plastizität der Tone. Als Ursache davon nimmt er eine eigentümliche Vereinigung von kolloidal gelösten Stoffen an, in der Porzellan- oder Tonmasse mit der eigentlichen Tonsubstanz (in reinster Form $\left.\mathrm{Al}_{2} \mathrm{O}_{3} \cdot 2\left(\mathrm{SiO}_{2}\right) \cdot 2 \mathrm{H}_{2} \mathrm{O}\right)$. Als solche Stoffe nennt er Kieselsäure, Alaunerde, organische Substanzen. Die eigentümliche Vereinigung, 
die Rohland annimmt, mufs doch wohl eine Agglutination, also eine Absorptionsverbindung sein, und die Entfernung dieser kolloidalen Stoffe mülste die Eigenschaft der Plastizität aufheben. $\mathrm{Ob}$ jedoch freie Kieselsäure oder Alaunerde allgemein in plastischen Tonen vorkommen, und dann in genügender Menge, ist nicht untersucht. Nach dem obigen sind die Laterite, auch wenn sie kolloidale freie, oder $\mathrm{SiO}_{2}$-arme $\mathrm{Al}_{2} \mathrm{O}_{3}$ enthalten, im allgemeinen nicht plastisch. Es kommt mir vor, dals die Plastizität und das Schwinden eine Eigenschaft des Verwitterungssilikats selbst ist, jedoch dals die Unstände, unter welchen dies stattfindet, noch zu unbekannt sind.

\section{Tabellen der Analysen.}

\section{Löfsböden.}

Tabelle I. Löss.' Niederlande $A$ bei Elsloo (Prov. Limburg) auf $3 \mathrm{~m}$ Tiefe Niederlande $B$ unter der Bauschicht des Zypenbergs bei Velp, Provinz Gelderland

\begin{tabular}{c|ccc|ccc} 
& \multicolumn{2}{|c}{} & \multicolumn{3}{c}{$B$} \\
Auszug & $\%$ & $\mathrm{Al}_{2} \mathrm{O}_{3}$ gelöst & Verhältnis & $\%$ & $\mathrm{Al}_{2} \mathrm{O}_{\mathbf{3}}$ gelöst & Verhältnis \\
$a$ & $1.8^{4}$ & $\mathbf{3 z}$ & $1.2^{3}$ & $\mathbf{3 . 2}$ \\
$c$ & 2.3 & $\mathbf{3 . 4}$ & 0.9 & $\mathbf{3 . 5}$ \\
Seh. & 1.7 & $\mathbf{2 . 0}$ & 0.6 & $\mathbf{2 . 5}$
\end{tabular}

2. Tonböden aus den Niederlanden, Java, Suriname.

Tabelle II. Leichterer Ton. ${ }^{2}$ Niederlande, Schlamm aus dem Wieringermeer bei der Provinz Nord-Holland.

Tabelle III. Leichterer Ton. ${ }^{3}$ Niederlande, Provinz Groningen bei Middelstum.
$a(1 / 2$
$c$
$0.8^{5}$
$1.7^{3}$
3.0
II

5
4.6
2.4
(1 St.) $\quad 2.6^{7}$
$3.14^{4}$
5.9
III
4.6
$6.8(?)$
$\mathbf{2 . 2}$

Tabelle IV. Sehwererer Ton. ${ }^{4}$ Niederlande. Friseher Schlamm aus dem Y-Busen vor der 'Trockenlegung.

Tabelle V. Schwererer Ton. ${ }^{5}$ Java - Kultivierter Boden, in der Nähe des Kening-Flusses, Residenz Rembang.
$a\left(\begin{array}{c}1 / 2 \\ e\end{array}\right.$
Sch.
IV

$\begin{array}{ll}1.8^{6} & 3.1^{1} \\ 4.4^{8} & 3.1^{2} \\ 5.0 & 2.2\end{array}$
V
6.9
3.0 $0^{0}$
4.2
$2.0^{2}$

1 Ausfülrliche Analyse unter meiner Leitung gemacht durch Herm H. W. Woupstra, Chem. cand. Abh. d. Kgl. Akad. v. Wissens. Amsterdam : (1900), 2. Sekt., Nr. 3.

2 Ausführliche Analyse in d. L. V. St. 37 (1889), 250-255.

${ }^{3}$ Diese Analyse ist von Dr. SJollems nach meiner Methode ausgeführt.

${ }^{4}$ Ausführliche Analyse: L. V.-St. 37 (1889), 241-249.

${ }^{5}$ Ausführliche Analyse: L. V.-St. 37 (1889), 274-278. 
Tabeile VI. Schwererer Ton. Surinam. ${ }^{1}$ Neu urbar gemacht. Kakaopflanzung Margarethenburg an der Nickerie in der Nähe der Meeresküste.

\begin{tabular}{|c|c|c|c|c|c|}
\hline \multicolumn{3}{|c|}{ VI 1. Analyse } & \multicolumn{3}{|c|}{ VI 2. Analyse. } \\
\hline Auszug & $\begin{array}{c}\% \mathrm{Al}_{2} \mathrm{O}_{3} \\
\text { gelöst }\end{array}$ & Verhältnis & Auszug & $\begin{array}{c}\% \mathrm{Al}_{2} \mathrm{O}_{3} \\
\text { gelöst }\end{array}$ & Verhältrıis \\
\hline$a(1 / 4, \mathrm{St})$. & 1.4 & 1.3 & $a(1 / 2 \mathrm{St})$ & 2.6 & 1.8 \\
\hline$b$ & 3.0 & 2.8 & $b l$ & & D \\
\hline$c_{\mathbf{1}}$ & 7.0 & 2.7 & & 8.0 & 2.8 \\
\hline$c_{2}$ & 2.2 & $8.7^{7}$ & $e$ & 3.6 & 2.8 \\
\hline Sch. & 8.8 & 2.0 & Seh. & 7.9 & 2.0 \\
\hline
\end{tabular}

Tabelle VII. Schwererer Ton. Suriname. Viele Jahre kultiviert. Kakaopflanzung Leliendaal an der Commewyne in der Nähe der Meeresküste.

\begin{tabular}{c|c|c}
\hline Auszug & $\begin{array}{c}\% \text { Alo } \mathrm{O}_{3} \\
\text { gelöst }\end{array}$ & Verhältnis \\
\hline$a(1 / 4 \mathrm{St})$. & $\mathbf{1 . 0}$ & $\mathbf{1 . 2 ^ { 5 }}$ \\
$b$ & 1.9 & $\mathbf{3 . 0}$ \\
$c_{1}$ & 4.9 & $\mathbf{3 . 2}$ \\
$c_{2}$ & 3.1 & $\mathbf{2 . 2}$ \\
Sch. & 11.7 & $\mathbf{2 . 0}$
\end{tabular}

3. Padasböden aus Java.

sogen. Padas, gar nicht plastisch, ein Konglomerat feiner Teilehen, durch ein Bindemittel zementiert. Vulkanischer Ursprung.

'Tabelle VIII. Java - Residenz Tegal - bei Djati Basang. Braunfarbig. Sehr hartes kleines Konglomerat.

\begin{tabular}{|c|c|c|c|c|c|c|c|c|c|c|}
\hline \multirow{2}{*}{ Auszug } & \multirow{2}{*}{$\begin{array}{l}{ }_{0}^{0} \mathrm{Al}_{2} \mathrm{O}_{3} \\
\text { gelöst }\end{array}$} & \multirow{2}{*}{$\left|\begin{array}{c}\text { Ver- } \\
\text { hältuis }\end{array}\right|$} & \multicolumn{6}{|c|}{$\%$} & \multirow{2}{*}{\multicolumn{2}{|c|}{ Zusarnmen $\%$}} \\
\hline & & & $\mathrm{SiO}_{2}$ & $\left|\mathrm{Fe}_{2} \mathrm{O}_{3}\right|$ & $\mathrm{CaO}$ & $\mathrm{MgO}$ & $\mathrm{K}_{2} \mathrm{O}$ & $\mathrm{Na}_{2} \mathrm{O}$ & & \\
\hline$k_{1}(5 \quad$ Мin. $)$ & 0.5 & 3.0 & $0.9^{2}$ & & & & & & $\mathrm{SiO}_{2}$ & 23.3 \\
\hline$k$ (30 Min.) & 2.8 & 1.3 & 2.2 & & $0.5^{6}$ & 0.5 & & & $\mathrm{Al}_{2} \mathrm{Cl}_{3}$ & 14.0 \\
\hline (i) Min.) & 1.7 & 3.0 & $3.1^{0}$ & $2.2^{7}$ & & & & 1 & $\mathrm{Fe}_{3} \mathrm{O}_{\mathrm{g}}$ & 8.7 \\
\hline$b_{1}$ (5 Min.) & 1.4 & 3.1 & $2.6^{1}$ & $2.1^{\circ}$ & & & & 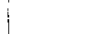 & $\mathrm{CaO}$ & 1.5 \\
\hline$b_{2}(30 \mathrm{Min})$. & 3.2 & 3.3 & $6.3^{4}$ & $3.5^{3}$ & 0.8 & $0.4^{2}$ & & 1 & $\mathrm{MgO}$ & 1.0 \\
\hline 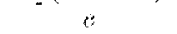 & 2.4 & 3.8 & $5.4^{0}$ & $0.8^{0}$ & & & & & Alkal. & 0.5 \\
\hline Sch. & 2.0 & 2.2 & $2.7^{1}$ & wenig & $0.1^{5}$ & $0.0^{7}$ & & & Unlöslich & 41.2 \\
\hline \multirow[t]{2}{*}{ Summs } & $: 14.0$ & ! & 23.3 & 8.7 & 1.5 & 1.0 & 0.2 & \pm 0.3 & $\overline{\bar{y}}\left(\begin{array}{ll}\alpha & 6.0 \\
\beta & 0.0\end{array}\right]$ & 0 \\
\hline & & & & \multicolumn{5}{|c|}{$\begin{array}{l}\alpha \text { Verlust übcr Schwefelsäure. } \\
\beta \text { Verlust bei } 100^{\circ} . \\
\gamma \text { Verlust bei Glühhitze. }\end{array}$} & $\stackrel{2}{\approx}\left\{\begin{array}{ll}\gamma & 3.2\end{array}\right\}$ & 100.2 \\
\hline
\end{tabular}

1 Ausfïhrliche Analysen von VI und VII. Landbouwkundig Tydschrift 1903, S. 314-355. Groningen, J. B. WoLters. 
Tabelle IX. Heligelb. Residenz Pl'eanger Regentschaften-Distrikt Bandong bei LembangDedjung, Brungkulen. Isose zusammenhängendes feines Konglomernt.

\begin{tabular}{|c|c|c|c|c|c|c|c|c|c|}
\hline \multirow{2}{*}{ Auszug } & \multirow{2}{*}{$\begin{array}{c}0 \mathrm{Al}_{2} \mathrm{O}_{3} \\
\text { gelöst }\end{array}$} & \multirow{2}{*}{ Verhältn. } & \multicolumn{5}{|c|}{ : } & \multirow{2}{*}{ Zusammen } & \\
\hline & & & $\mathrm{SiO}_{3}$ & $\mathrm{Fe}_{2} \mathrm{O}_{3}$ & $\mathrm{CaO}$ & $\mathrm{MgO}$ & $\mathrm{K}_{2} \mathrm{O}$ & & 10 \\
\hline 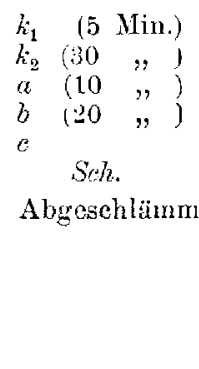 & $\begin{array}{l}4.0 \\
1.9 \\
6.0 \\
1.3 \\
1.6 \\
0.3 \\
-\frac{2.6^{5}}{4} 15.1\end{array}$ & $\begin{array}{l}0.3 \\
0.9 \\
2.5 \\
2.5 \\
2.7 \\
2.5\end{array}$ & $\begin{array}{l}0.7^{3} \\
1.0^{3} \\
8.8^{0} \\
1.9 \\
2.5 \\
1.5 \\
4.4^{3}\end{array}$ & $\begin{array}{l}5.7^{5} \\
0.9^{2} \\
00^{5}\end{array}$ & $\begin{array}{l}102 \\
0.3^{6} \\
0.3^{4}\end{array}$ & $\begin{array}{l}0.1^{9} \\
0.1^{2} \\
0.1^{2}\end{array}$ & \pm 0.2 & 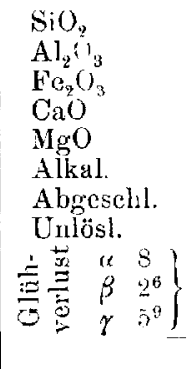 & $\begin{array}{r}15.0 \\
15.1 \\
6.7 \\
1.0 \\
0.4 \\
- \\
7.4 \\
38.5 \\
\\
16.5 \\
100.3\end{array}$ \\
\hline
\end{tabular}

Tabelle X. Rot. In der Nähe von Padas IX bei Tjipanas. Hartes feines Konglomerat.

\begin{tabular}{|c|c|c|c|c|c|c|c|c|c|}
\hline \multirow{2}{*}{ Auszug } & \multirow{2}{*}{$\begin{array}{c}\mathrm{Al}_{2} \mathrm{O}_{3} \\
\text { gelöst }\end{array}$} & \multirow{2}{*}{ Verhältn. } & \multicolumn{5}{|c|}{$\%$} & \multirow{2}{*}{\multicolumn{2}{|c|}{ Zusammen $\%$}} \\
\hline & & & $\mathrm{SiO}_{2}$ & $\mathrm{Fe}_{2} \mathrm{O}_{3} \mid$ & $\mathrm{CaO}$ & $\mathrm{MgO}$ & $\mathrm{K}_{2} \mathrm{O}$ & & \\
\hline 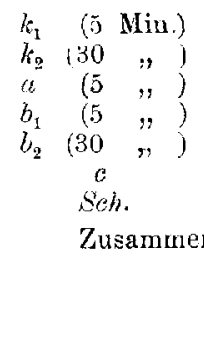 & $\begin{array}{l}4.5^{5} \\
5.0^{2} \\
7 . .^{2} \\
2.8^{1} \\
2.3^{8} \\
1.3^{4} \\
0.9^{1} \\
: 24.2\end{array}$ & 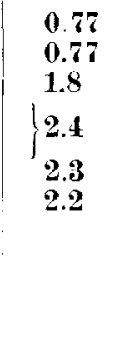 & $\begin{array}{l}2.0^{6} \\
2.2^{3} \\
7.4^{8} \\
7.3^{3} \\
1.8^{5} \\
1.1^{9} \\
22.2\end{array}$ & $\begin{array}{c}1.1^{5} \\
6.5^{0} \\
4.8^{1} \\
1.3^{5} \\
0.3^{2} \\
14.1\end{array}$ & $\begin{array}{l}0.1^{3} \\
0.3 \\
0.2^{4} \\
0.2^{2} \\
0.1^{3} \\
\frac{0.0^{7}}{1.1}\end{array}$ & $\begin{array}{l}0.1^{6} \\
0.1^{0} \\
0.1^{4} \\
0.1^{4} \\
0.1^{3} \\
0.6^{7}\end{array}$ & \pm 0.2 & 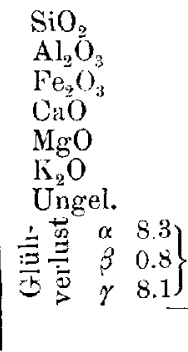 & $\begin{array}{r}22.2 \\
24.2 \\
14.1 \\
1.1 \\
0.7 \\
0.2 \\
20.2 \\
\\
17.2 \\
99.9\end{array}$ \\
\hline
\end{tabular}

4. Vulkanische Böden.

Tabelle XI. Java ${ }^{1}$. Residenz Pasoeroean. Distrikt Malang.

A. von Gondang Legie, B. von Sirka Anjar, zwischen den Vulkamen: der Kloet und der Semeroe.

\begin{tabular}{|c|c|c|c|c|c|c|c|}
\hline \multirow{3}{*}{ Auszug } & \multirow{3}{*}{$\begin{array}{c}\% \mathrm{Al}_{2} \mathrm{O}_{3} \\
\text { gelöst }\end{array}$} & \multirow{3}{*}{$\begin{array}{c}\text { Ver- } \\
\text { bältnis }\end{array}$} & \multicolumn{4}{|c|}{0} & \multirow{3}{*}{ Das Unlösliche } \\
\hline & & & \multirow{2}{*}{$\begin{array}{l}\mathrm{Hu}- \\
\text { mus }\end{array}$} & \multicolumn{2}{|c|}{ Gliihverlust } & \multirow{2}{*}{$\mid \begin{array}{l}\text { Unlös- } \\
\text { lich }\end{array}$} & \\
\hline & & & & $\alpha$ & $\beta$ u. $\gamma$ & & \\
\hline & & A. & & & & & Sanidinfeldspat \\
\hline$c$ & 17.28 & 2.2 & 3.8 & 6.8 & $6.3^{5}$ & 36.5 & mit Glasein- \\
\hline Sch. & 0.25 & \pm 3.6 & & & & & 3.2 Magnesit, \\
\hline (" & 11.2 & B. & 3.4 & 3.7 & 3.4 & 56.0 & $\begin{array}{l}\text { Plagioklasen, } \\
\text { Hornblende, } \\
\text { Magnetit. } \\
\text { Körnergrößs } \\
\text { einzelne Mikrons } \\
\text { bis } 0.9 \mathrm{~mm} \text {. }\end{array}$ \\
\hline
\end{tabular}

${ }^{1}$ Siehe die ausführliche Analyse von $\mathrm{XI}$ in $L . V . S t .37$ (1890), $269-$ von XII S. 258. 
Tabelle XII. Urwaldboden.' Sumatra, Residenz Deli bei Medan, war das erste Mal mit Tabak bepflanzt. Hoher Humusgehalt. Rotbraum.

\begin{tabular}{|c|c|c|c|c|c|}
\hline \multicolumn{3}{|c|}{ Erste Analyse. } & \multicolumn{3}{|c|}{ Zweite Analyse. } \\
\hline Auszug & $\begin{array}{c}\text { \% } \mathrm{Al}_{3} \mathrm{O}_{3} \\
\text { gelöst }\end{array}$ & $\left|\begin{array}{c}\text { Ver- } \\
\text { hältuis }\end{array}\right|$ & Auszug & $\begin{array}{c}\% \mathrm{Al}_{2} \mathrm{O}_{3} \\
\text { gelöst }\end{array}$ & Verhältnis \\
\hline$a(30$ Min. $)$ & 1.6 & 0.9 & $k_{1}$ & 11.75 & 0.97 \\
\hline$a_{1}$ bei $100^{\circ}(30 \mathrm{M})$. & $6.3^{4}$ & 09 & $k_{\mathrm{z}}$ & 12.6 & 2.1 \\
\hline$b$ & $4.5^{6}$ & & & 24.35 & \\
\hline $\begin{array}{c}c \\
\text { Sch. } \\
\text { Zusimmeu: }\end{array}$ & $\begin{array}{l}12.8^{4} \\
\frac{1.2^{8}}{26.6}\end{array}$ & 3.2 & 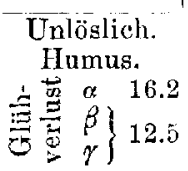 & $\begin{array}{r}20.5 \\
5.1 \\
18.7\end{array}$ & $\begin{array}{l}\text { Sanidinfeldspat mit Glaseinschl. } \\
\text { Plagioklasen. Viel dunkelgrüne } \\
\text { Hornblende. Etwas Angit. } 4.3 \% \\
\text { Magnetit. KörnergröBe der Krist. } \\
3 \text { Mikrons bis } 0.5 \mathrm{~mm} \text {. }\end{array}$ \\
\hline
\end{tabular}

Tabelle XIII. Urwaldboden. ${ }^{1}$ Sumatra bei Medan. Graufarbig.

\begin{tabular}{|c|c|c|c|c|c|}
\hline Auszug & $\begin{array}{c}\%_{0} \mathrm{Al}_{2} \mathrm{O}_{3} \\
\text { gelöst }\end{array}$ & $\begin{array}{l}\text { Ver- } \\
\text { hältnis }\end{array}$ & $0 \%$ & & Das Unlösliche \\
\hline$a(30$ Min.) & 2.9 & 2.1 & Humus & 32.2 & \\
\hline$c$ & 7.9 & 9.7 & 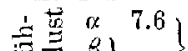 & 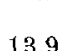 & War wie im \\
\hline Ss. & $\frac{4.0}{14.8}^{10.8}$ & 2.0 & 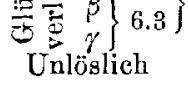 & $\begin{array}{l}13.9 \\
47.7\end{array}$ & $\begin{array}{l}\text { Deliboden XII (kem } \\
\text { Quarz) } 0.9 \% \text { Magnetit. }\end{array}$ \\
\hline
\end{tabular}

\section{Lateritische Böden.}

Tabelle XIV. Plastischer Laterit mit wenig $\mathrm{Fe}_{2} \mathrm{O}_{3}$. Surinam - hohe Ufer der Unten-Nickerie.

1. Analyse betrifft die ausgesuchten Teile der Erde, welche keine rote Adern zcigten; die zweite die Frde, wia sie gesammelt war.

1. Analyse.

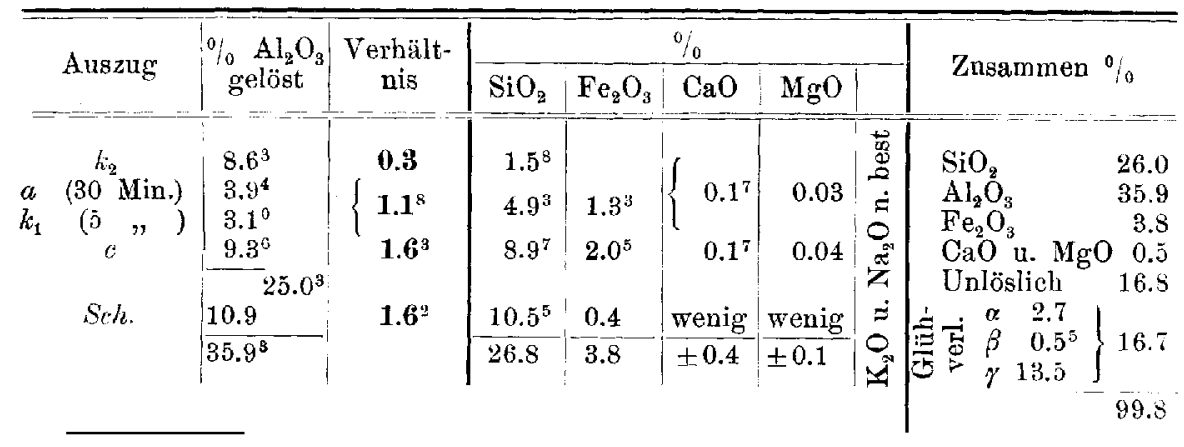

1 Siehe die ausführliche Analyse von XI in L. V. St. 37 (1890), $269-$ von XII S. 258. - von XIII S. 265. 
2. Analyse.

$b$ 18.6

$4: 0: 6.3: \pm 0.2$

Zusammen

$25 \%$

17, Glühverlust

Die $16.7 \%$ unlöslichen Teile bestanden aus: Quarz, Oligoklas, Sillimannit, Disthen, Zirkon und Illmenit (Titaneisenstein), kristallinisches Hydrargillit wurde nicht beobachtet.

24 , Abgeschlïmmt

32 "Bei der Schlämme zïrück bleibend

Tabelle XV-XVII. Drei eisenreichere nicht plastische Laterite aus Surinam.

Tabelle XV. Erde, durch Verwitterung eines Diabas oder Dioritgesteins entstanden. Am Ful's des Avenovero-Falls. Sekundäre Lagerstätte.

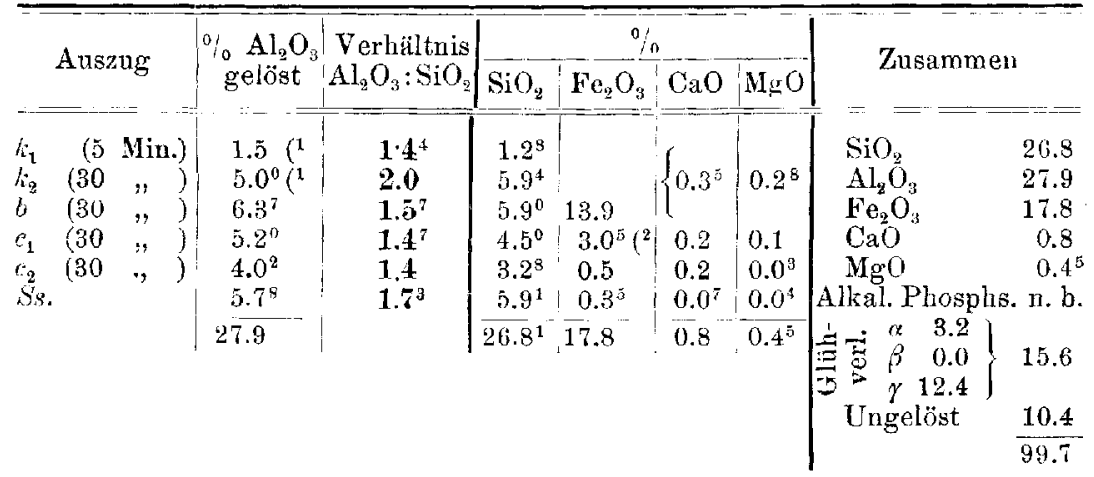

Tabelie XVI. Erde, durch Verwitterung eines Diabas- oder Dioritgesteing eutstanden. Sekundäre Lagerstätte. Am steilen Ufer eines „Kreekje" (Baches) an der linken Seite der Blanche Marie.

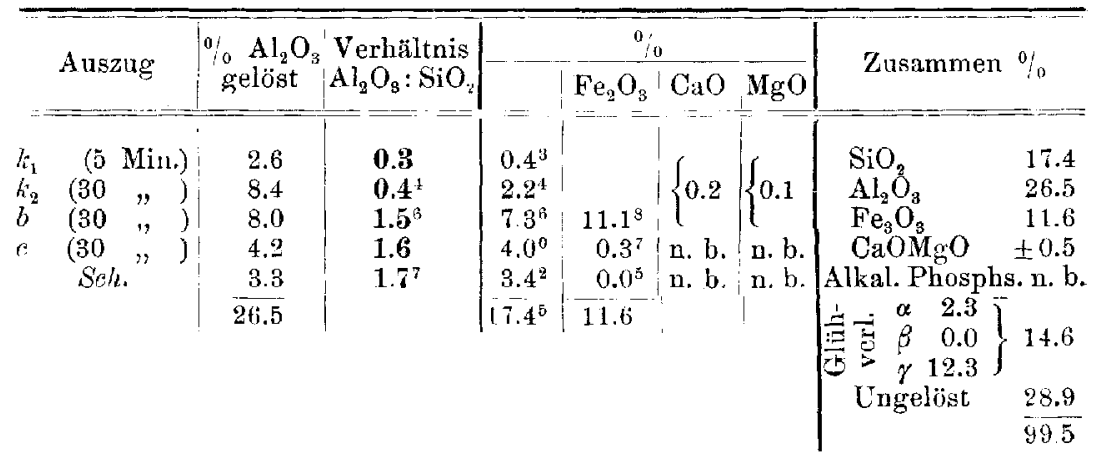

1 Nachdem bei einer ersten Analyse allein $k_{2}$ bestimmt war und $6.4^{5} \%$ $\mathrm{Al}_{2} \mathrm{O}_{3}$ und das Verhältnis 2.1 ergeben hatte, wurde in einer doppelten Menge Erde $(5 \mathrm{~g})$ erst $k_{1}$ und darauf $k_{2}$ bestimmt. Es wurde also im ersten Auszug $k_{1}$ das Verhältnis 1.4 erhalten, und erst in $k_{2}$ ein höherer Ki€selsäuregehalt. Die Summe von $k_{1}$ und $k_{2}$ ergibt das Verbältnis $1.9^{3}$.

${ }^{3}$ Diese Menge Eisenoxyd rührt grölstenteils vom Illmenit her, welches durch die konzentrierte Salzsäure bei Siedehitze gelöst wird. 
Tabelle XVII. Erde, sehr eisenreich aus dem Bette einer Kreck, nördlich ron der Blanche Marie.

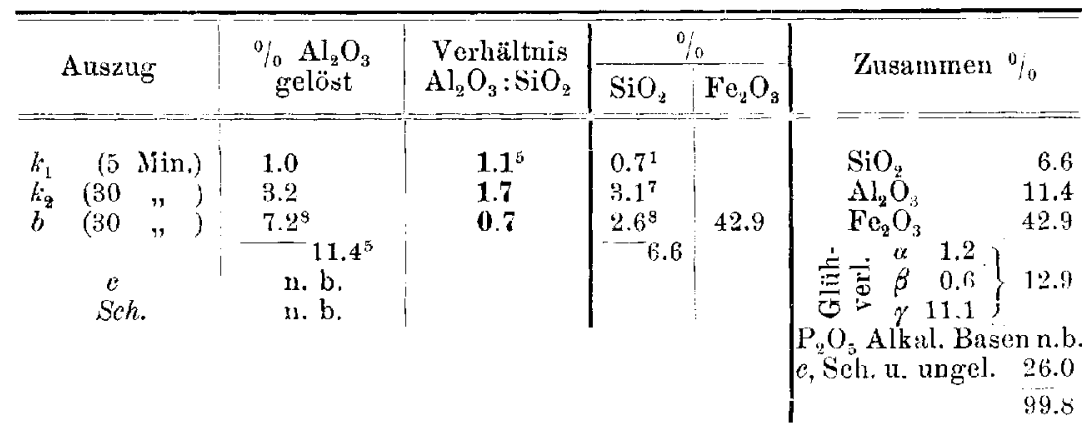

Diese Iatzrite sind aus Diabas oder Diorit entstanden.

Das U.V.S. enthält Sillimannit, Disthen, Zirkon, 'Titaneisenstein und daneben Feldspat (normale) und Quarz. Hydrargillit wurde nieht beobachtet. Die Körnchen sind bei XVII durch die grofse Menge Eisenoxyd arn festesten zusammenzementiert. Bei $X V$ ist der Zusammenhang viel loser. Sie sind nicht plastisch.

In XV beträgt die Grölse der Kömchen 2.5-11 Mikrons, einzelne gröfser bis $0.3 \mathrm{~mm}$; die Sillimannitkörachen sind im allgemeinen die grölsten. Die Erde XVI, welche $1 / 3$ ihres Gewichts an schwersten Teilen enthält, hat gröfsere Quarzkörnehen (bis $0.5 \mathrm{~mm}$ ).

Tabelle XVIII, Iaterit mit krist. Hydrargillit. Suriuam. Distrikt Nickerie. - Vom rechten Ufer der Fallawatra, in der Nähe des Cremer-Wasserfalles.

1. Analyse.

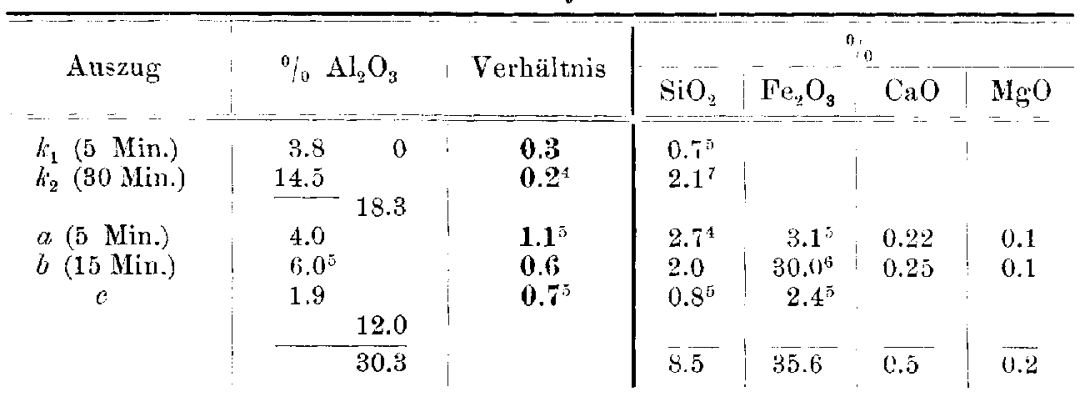

2. Analyse.

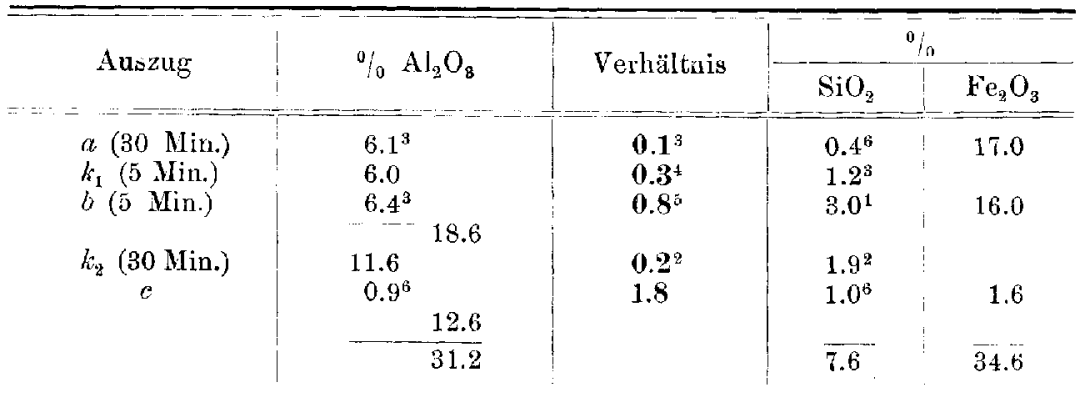




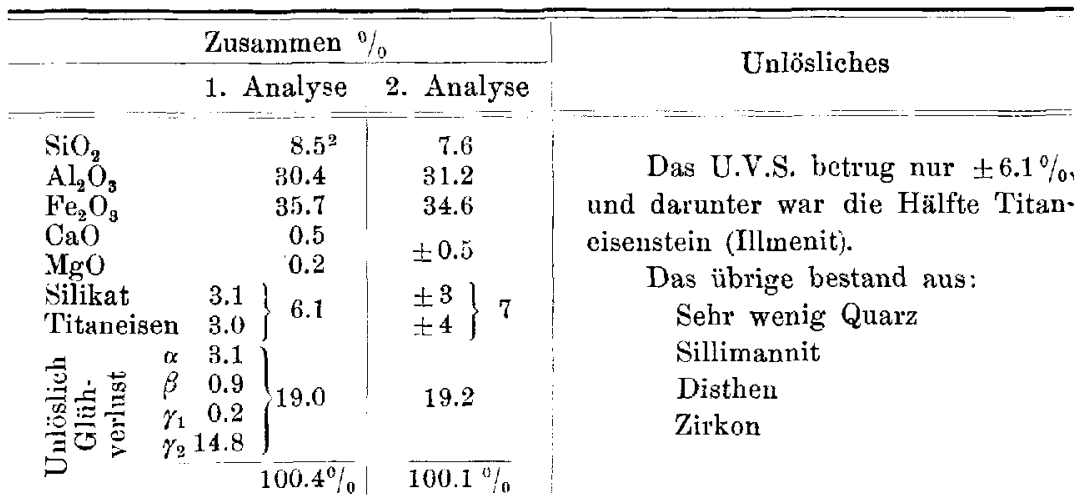

Tabelle XIX-XX. Laterit auf primärer Lagerstätte. - Seychellen Inseln.

Tabelle XIX. Diorit-Laterit.

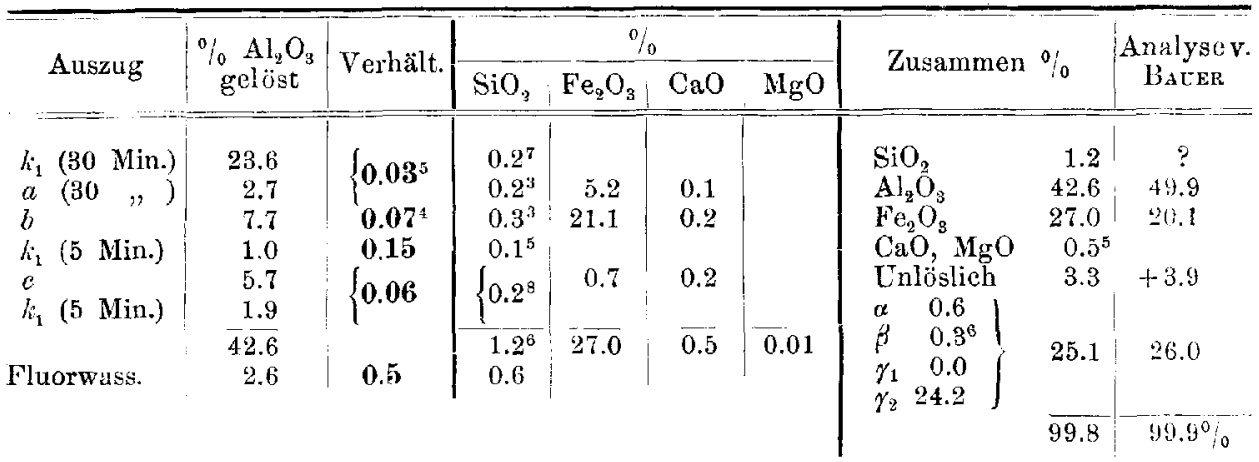

Tabelle XX. Granit-Laterit.

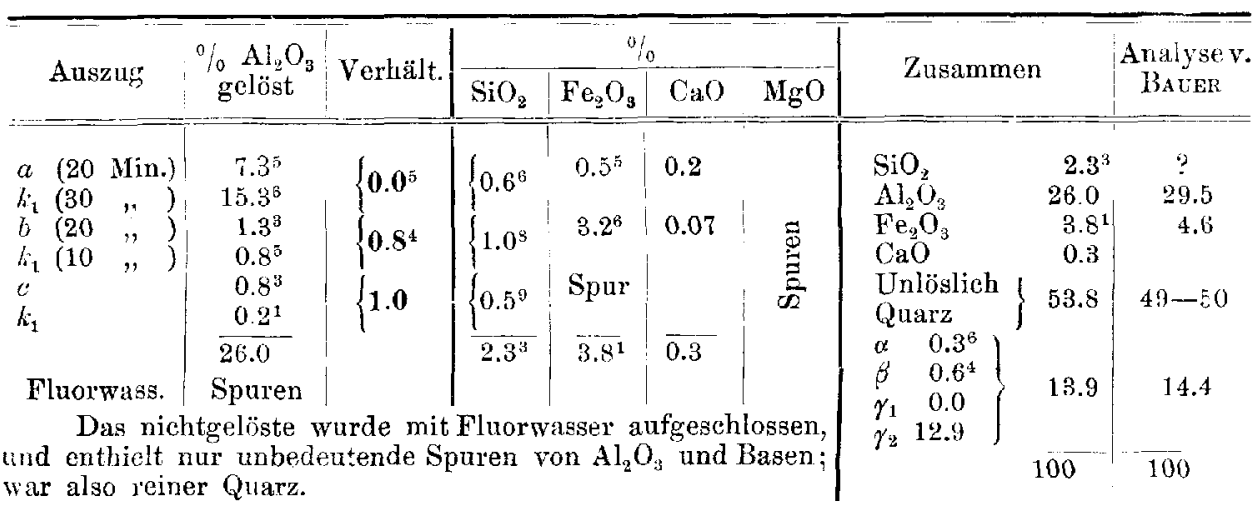


Tabelle XXI-XXIV. Alkalinische Basen.

Tabelle XXI. Nach Entfernung von $\mathrm{NaCl}, \mathrm{MgCl}_{2}, \mathrm{CaSO}_{4}$ durch Wasser und nach Abzug des kohlensauren Kalkcs.

Auf $1 \mathrm{Mol} . \mathrm{Al}_{2} \mathrm{O}_{3}$.

\begin{tabular}{l}
\hline \\
\hline
\end{tabular}

Tabelle XXII-XXIII. Alkalinische Basen in den auffolgenden Auszügen.

Tabelle XXII. Ton aus Suriname (VI).

\begin{tabular}{|c|c|c|c|c|c|c|}
\hline \multirow{2}{*}{$\% \quad \mathrm{Al}_{2} \mathrm{O}_{3}$} & \multirow{2}{*}{$\begin{array}{c}\text { Verhältnis } \\
\mathrm{zu} \mathrm{SiO}_{2} \\
\text { in } \mathrm{Mol}\end{array}$} & \multirow{2}{*}{ Auszug } & \multicolumn{4}{|c|}{ Auf 1 Mol. $\mathrm{Al}_{2} \mathrm{O}_{3}$} \\
\hline & & & Mol. $\mathrm{CaO}$ & Mol. $\mathrm{MgO}$ & Mol. $\mathrm{K}_{2} \mathrm{O}$ & Mol. $\mathrm{Na}_{2} \mathrm{O}$ \\
\hline $1.2^{3}$ & 1.3 & $a$ & 0.33 & 0.83 & 0.10 & \\
\hline $3.4^{4}$ & 2. & $b$ & 0.05 & 0.32 & $0.07^{7}$ & \\
\hline $4.6^{2}$ & 2.7 & $c_{t}$ & $0.02^{7}$ & 0.14 & $0.08^{6}$ & $0.01^{5}$ \\
\hline $2.5^{4}$ & 2.7 & $c_{2}$ & $0.02^{8}$ & 0.10 & $0.09^{6}$ & \\
\hline $1.8^{8}$ & 2.7 & $c_{3}$ & $0.03^{\circ}$ & 0.08 & $0.11^{8}$ & \\
\hline $8.8^{6}$ & 2.0 & Seb. & $0.00^{5}$ & 0.06 & 0.17 & $0.02^{5}$ \\
\hline
\end{tabular}

Tabelle XXIII.

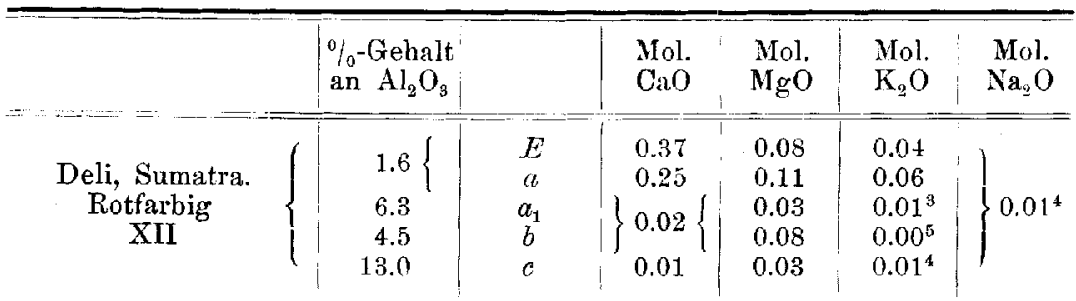


Tabelle XXIII. Fortsetzung.

\begin{tabular}{|c|c|c|c|c|c|c|}
\hline & $\begin{array}{l}\% / 0^{-G e h a l t} \\
\text { an } \mathrm{Al}_{2} \mathrm{O}_{3}\end{array}$ & & $\begin{array}{l}\mathrm{Mol} . \\
\mathrm{CaO}\end{array}$ & $\begin{array}{l}\text { Mol. } \\
\text { MgO }\end{array}$ & $\begin{array}{l}\text { Mol. } \\
\mathrm{K}_{2} \mathrm{O}\end{array}$ & $\begin{array}{l}\mathrm{Mol} . \\
\mathrm{Na}_{2} \mathrm{O}\end{array}$ \\
\hline $\begin{array}{l}\text { Deli, Sumatra. } \\
\text { Graufarbig. XII }\end{array}$ & $\begin{array}{l}2.9 \\
7.9\end{array}$ & $a$ & $\begin{array}{l}0.24 \\
0.10\end{array}$ & $\begin{array}{l}0.17 \\
0.05\end{array}$ & $\begin{array}{l}0.02 \\
0.02^{5}\end{array}$ & $\begin{array}{l}0.04 \\
1.0\end{array}$ \\
\hline Gelbe Padas. IX & $\begin{array}{r}11.9 \\
1.3 \\
1.6\end{array}$ & $\begin{array}{c}k_{1}, k_{2}, a \\
b \\
e\end{array}$ & $\begin{array}{l}0.04 \\
0.5 \\
0.4\end{array}$ & $\begin{array}{l}0.04 \\
0.2 \\
0.2\end{array}$ & & \\
\hline Rote Padas. X & $\begin{array}{r}16.7 \\
2.8 \\
2.4 \\
1.3\end{array}$ & $\begin{array}{c}k_{1}, k_{2}, a \\
b_{1} \\
b_{2} \\
c\end{array}$ & $\begin{array}{l}0.04 \\
0.15 \\
0.15 \\
0.17\end{array}$ & $\begin{array}{l}0.24 \\
0.1 \\
0.15 \\
0.26\end{array}$ & & \\
\hline Braune Padas. VIIT & $\begin{array}{l}5.0 \\
4.6 \\
\mathbf{2 . 4}\end{array}$ & $\begin{array}{c}k_{1}, \\
\frac{k_{2}}{b}, a \\
e\end{array}$ & $\begin{array}{l}0.2 \\
0.3\end{array}$ & $\begin{array}{l}0.25 \\
0.16 \\
0.3\end{array}$ & & \\
\hline
\end{tabular}

Tabelle XXIV. Prozent in verdünnter Essigsäure löslich nach Abzug der Karbonate, Chlorüre und Sulfate.

\begin{tabular}{|c|c|c|c|c|}
\hline & $\% \mathrm{CaO}$ & $\% \mathrm{MgO}$ & ${ }_{10} \mathrm{~K}_{2} \mathrm{O}$ & $\% \mathrm{Na}_{8} \mathrm{O}$ \\
\hline IV Y & 0.27 & 0.7 & 0.10 & 0.11 \\
\hline Ton $\{$ II Wieringermeer & 0.39 & 0.25 & $0.14^{5}$ & 0.05 \\
\hline I V Rembang (Kening) & 0.23 & 0.14 & 0.10 & 0.07 \\
\hline XII Deli & 0.33 & 0.05 & $0.06^{5}$ & 0.03 \\
\hline Vulk. $\{$ XI $\{$ Gondang I Legie & 0.42 & 0.08 & 0.09 & $0.04^{5}$ \\
\hline${ }^{A 1}\{$ Sirka Anjar & 0.34 & 0.06 & 0.12 & $0.04^{5}$ \\
\hline
\end{tabular}

Tabelle XXV. Wassergehalt des V.S. (Bei der Aunahme, daf's an $1 \mathrm{Mol}$. $\mathrm{Fe}_{2} \mathrm{O}_{3}$ im Boden \pm 1 Mol. $\mathrm{H}_{2} \mathrm{O}$ festgebunden ist.)

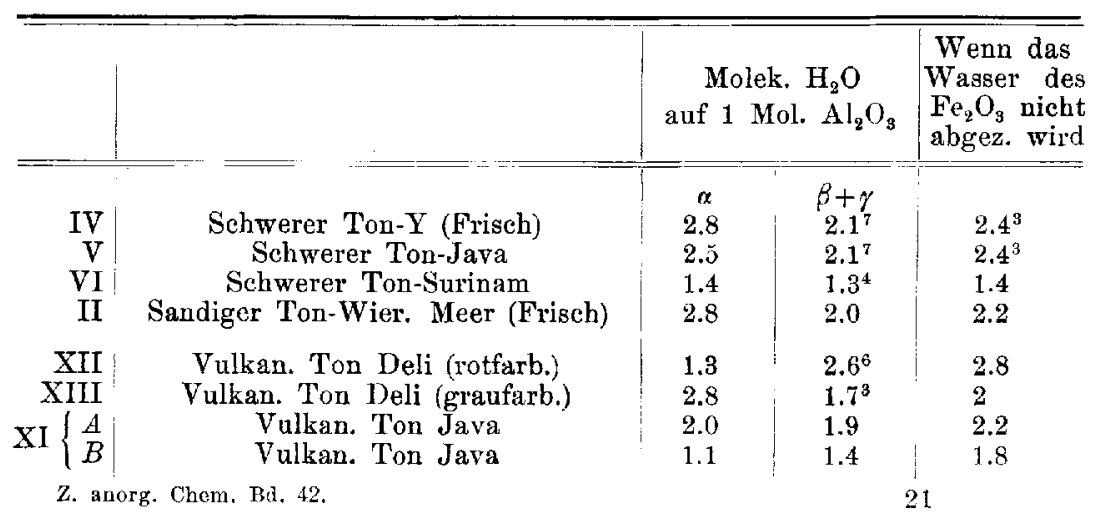


Tabelle XXV. (Fortsetzung.)

\begin{tabular}{|c|c|c|c|c|c|c|}
\hline \multirow[b]{2}{*}{$\begin{array}{r}\text { IX } \\
\text { X } \\
\text { VIII }\end{array}$} & \multirow[b]{2}{*}{$\begin{array}{c}\text { Padas Java (gelbe) } \\
\text { Padas Java (rote) } \\
\text { Padas Java (braune) }\end{array}$} & \multicolumn{4}{|c|}{$\begin{array}{c}\text { Molek. } \mathrm{H}_{2} \mathrm{O} \\
\text { auf } 1 \text { Mol. } \mathrm{Al}_{2} \mathrm{O}_{3}\end{array}$} & $\begin{array}{l}\text { Wenn das } \\
\text { Wasser des } \\
\mathrm{Fe}_{2} \mathrm{O}_{\mathrm{g}} \text { nicht } \\
\text { abgez. wird }\end{array}$ \\
\hline & & $\begin{array}{l}\quad k \\
\pm 3 \\
2 \\
2.5\end{array}$ & $\begin{array}{c}\beta \\
\pm 1 \\
0.2\end{array}$ & $1.2^{5}$ & $\begin{array}{l}\gamma \\
1.8 \\
1.5\end{array}$ & $\begin{array}{l}2.2 \\
1.9 \\
1.6\end{array}$ \\
\hline $\begin{array}{r}\text { XIV } \\
\text { XVII } \\
\text { XVIII }\end{array}$ & $\begin{array}{l}\text { Lateritton Surinam (plastisch) } \\
\text { Latexitton Surinam (eisenreich) } \\
\text { Lateritton Surinam (viel Hydrar- } \\
\text { gillit und viel } \mathrm{Fe}_{2} \mathrm{O}_{8} \text { ) }\end{array}$ & $\begin{array}{l}0.4^{5} \\
0.6 \\
0.3\end{array}$ & $\begin{array}{l}0.1^{2} \\
0.6\end{array}$ & 2.9 & 2.1 & $\begin{array}{l}2.2 \\
5.5 \\
2.8\end{array}$ \\
\hline $\mathrm{XX}$ & $\begin{array}{l}\text { Lateritton Seychelleninseln (Granit) } \\
\text { (viel Hydrargillit und } \mathrm{Fe}_{3} \mathrm{O}_{3} \text { ) }\end{array}$ & 0.08 & 0.14 & & $2.7^{6}$ & 2.8 \\
\hline XIX & $\begin{array}{l}\text { Lateritton Seychelleniosel (Diorit) } \\
\text { (viel Hydrargillit) }\end{array}$ & 0.08 & 0.2 & & 2.7 & 3.2 \\
\hline
\end{tabular}

Leiden, Anorg. Laboratorium der Universilät, 4. August 1904.

Bei der Redaktion eingegangen am 15. August 1904.

\title{
Die Absorption von Wasser durch Ton.
}

\author{
Durch J. M. van BemMelen.
}

Das Absorptionsvermögen des Bodens für Wasser und Gase ist ein wichtiger Faktor ihrer Fruchtbarkeit. Bei Tonböden kommt dieses Vermögen besonders dem Ton zu (auch dem Humus) und ist abhängig von der Zusammensetzung und von den physikalischen Eigenschaften des Verwitterungssilikats und des Humus. Dadurch werden die sogenannte Hygroskopizität und Wasserkapazität bestimmt. Unter Hygroskopizität wird verstanden die Menge Wasser, welche als Wasserdampf durch die über Schwefelsäure oder bei $100^{\circ}$ getrocknete Erde absorbiert werden kann. Unter Wasserkapazität die Menge Wasser, welche die Erde als Wasserdampf und als flüssiges Wasser zusammen absorbieren kann; dabei kommt auch die Bodenstruktur in Betracht.

Dieses Wasser ist absorptiv gebunden. Es steht also nicht in

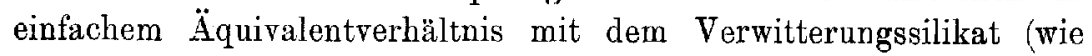
auch mit dem Gehalt an Eisenoxyd, Humus) und ist nicht mit Sprüngen abhängig ron dem Wasserdampfdruck und der Temperatur des Mediums, sondern ist kontinuierlich davon abhängig. Von der Temperatur ist es nur in geringem Grade abhängig. Dieselben Gesetze gelten hier wie für die kolloidalen Körper im allgemeinen. Das Gewicht einer ton- und humushaltigen Erde ist also nicht konstant, 